\title{
Kriegswesen und Herrschaftsbildung der Wettiner im späten Mittelalter
}

\author{
von \\ ALEXANDER QUERENGÄSSER
}

Die deutsche Militärgeschichte hat in den letzten 20 Jahren einen beträchtlichen Aufschwung erlebt. Dies gilt insbesondere für die sogenannte neuere Militärgeschichte, welche über das Feld von Kriegen und Schlachten hinausgehend vor allem soziale und wirtschaftliche Aspekte des Heerwesens analysiert. ${ }^{1}$ Einen großen Beitrag hierzu leisten die Veröffentlichungen des 1996 gegründeten „Arbeitskreises Militärgeschichte Frühe Neuzeit e. V.“ Innerhalb der Reihe „Herrschaft und soziale Systeme in der Frühen Neuzeit" erschienen seitdem fast zwanzig Monografien und Sammelbände, welche sich bevorzugt mit dem Verhältnis von Herrschaft und Militär in der Frühen Neuzeit auseinandersetzen. ${ }^{2}$

Die deutsche Forschung greift damit Fragen und Methoden der englischen und französischen Geschichtsschreibung auf. 1955 legte Michael Roberts' Aufsatz über die Militärische Revolution ${ }^{3}$ den Grundstein für die nachfolgenden Theorien englischer und amerikanischer Militärhistoriker. Roberts sah in den tief greifenden Umwälzungen des schwedischen Militärsystems zwischen 1550 und 1650 den Motor für Staats- bzw. Herrschaftsbildungsprozesse. Obwohl inzwischen von vielen Forschern kritisiert und bezogen auf das von ihm gewählte Beispiel auch abgelehnt, hat sich der Begriff der Militärischen Revolution für frühneuzeitliche Strukturwandlungsprozesse im Herrschafts- und Militärwesen verfestigt.

Eine akribische Suche nach einem wirklich „revolutionären“ Strukturwandel muss jedoch konsequenterweise weiter in die Geschichte zurückgehen bis hin zum Spätmittelalter. Auch diese Epoche hat die neuere Militärgeschichte, wenn auch weit weniger umfangreich als die Frühe Neuzeit, bereits in den Blick genommen. Im Jahr 2000 verfasste Peter Moraw für einen von Werner Rösener herausgegebenen Sammelband seinen Aufsatz „Staat und Krieg im deutschen Spätmittel-

1 Hierzu einführend: Ralf Pröve, Die frühneuzeitliche Militärgeschichte in den letzten zwanzig Jahren (1990-2010). Konzepte, Methoden und Arbeitsfelder, in: Hitotsubashi Journal of Law and Politics 39 (2011), S. 31-41; Ders., Vom Schmuddelkind zur anerkannten Subdisziplin? Die „neue Militärgeschichte“ der Frühen Neuzeit. Perspektiven, Entwicklungen, Probleme, in: Geschichte in Wissenschaft und Unterricht 51 (2000), S. 597-612.

2 Geschichte, Veranstaltungs- und Publikationstätigkeit des Vereins lassen sich am einfachsten auf seiner Internetpräsenz recherchieren: http://www.amg-fnz.de/.

3 Michael Roberts, The Military Revolution, 1560-1660, in: Ders., Essays in Swedish History, Minneapolis 1967, S. 195-225. 
alter". ${ }^{4}$ Moraw geht darin allerdings nur kurz, am Beispiel der 1427 ausgeschriebenen Reichstürkensteuer, auf Herrschaftsbildungsprozesse ein. Neuere Studien, etwa die Arbeiten von Uwe Tresp, beschäftigen sich mehrheitlich mit dem Kriegswesen des 15. Jahrhunderts, weniger mit deren Auswirkungen auf die frühmoderne Herrschaft. Erst mit seinem 2013 publizierten Handbuch im Rahmen der „Enzyklopädie deutscher Geschichte“ dehnte der Nestor der modernen deutschen Militärgeschichtsschreibung, Bernhard R. Kroener, die Grenzen militärischer und herrschaftlicher Entwicklungen in der Frühen Neuzeit auch auf das Spätmittelalter aus. ${ }^{5}$ Kroener griff dabei auf die Thesen des Engländers Clifford J. Rogers zurück, welcher Ansätze der von seinen Landsleuten Roberts, Parker und Black im 16. bis 18. Jahrhundert verorteten Militärischen Revolution bereits im Spätmittelalter erkannte. ${ }^{6}$

Dass der Krieg und das Aufkommen der sächsischen Stände in einem Zusammenhang standen, ist nicht unbedingt neu und wurde so auch schon von Jörg Rogge in seiner Geschichte der Wettiner formuliert. ${ }^{7}$ Allerdings betrachteten sächsische Historiker dabei eher den Krieg und die von ihm verursachten Kosten als Einzelereignis. Dass diese Kosten durch einen Strukturwandel des spätmittelalterlichen Militärwesens in die Höhe schossen, wurde dabei bisher noch nicht erwogen. Diese Zusammenhänge möchte der vorliegende Aufsatz aufzeigen. Zunächst soll der strukturelle Wandel vom Lehnsaufgebot zum Söldnerheer beschrieben werden. Zwei wichtige Exkurse bilden die wachsende Bedeutung von Schwarzpulverwaffen und die dadurch hervorgerufenen Veränderungen im Befestigungswesen. In einem letzten Abschnitt soll dann untersucht werden, wie die Wettiner ihre Kriege finanzierten und wie die geschilderten Veränderungen im Heereswesen zum Herrschaftsbildungsprozess beitrugen.

4 Peter Moraw, Staat und Krieg im deutschen Spätmittelalter, in: Werner Rösener (Hg.), Staat und Krieg. Vom Mittelalter bis zur Moderne, Göttingen 2000, S. 82-112.

5 Bernhard R. Kroener, Kriegswesen, Herrschaft und Gesellschaft 1300-1800 (Enzyklopädie deutscher Geschichte 92), München 2013, S. XIII f.: „Vor allem die angelsächsische Forschung hat in den vergangenen Jahren in dieser Epoche zumeist unter taktischem, technischem und organisatorischem Blickwinkel den Begriff einer „Infantry Revolution" verortet. Die schrittweise Entwicklung des Fußvolkes zum zentralen Element der Kriegsführungstätigkeit bedurfte gleichzeitig sozialer, ökonomischer und organisatorischer Voraussetzungen und bewirkte veränderte kulturelle Wahrnehmungen, Welt- und Gesellschaftsbilder, unter denen sich das Kriegsvolk allmählich zum Militär entwickelte."

6 Clifford J. Rogers (Hg.), The Military Revolution Debate. Readings on the Military Transformation of Early Modern Europe, Boulder u. a. 1995.

7 Jörg Rogge, Die Wettiner. Aufstieg einer Dynastie im Mittelalter, Ostfildern 2005, S. 159. 


\section{Vom Lehnsaufgebot zum Söldnerheer}

Söldner als auf Zeit „mietbare“ Krieger sind so alt wie die Geschichte des Krieges, und natürlich gab es sie auch im Mittelalter. Jede Gesellschaft, deren Wirtschaft auf Arbeitsteilung beruht, bringt soziale Schichten hervor, die nicht am ökonomischen System partizipieren können und nach alternativen Erwerbsmöglichkeiten suchen müssen. In Zeiten des Krieges bot der Waffendienst daher verlockende Chancen. ${ }^{8}$

Dennoch stützte sich das hochmittelalterliche Heerwesen vor allem auf die Lehnsaufgebote des Adels, auf den gut gerüsteten Ritter zu Ross und dessen Gefolgschaft. 9 Auf solchen Aufgeboten baute auch das wettinische Heerwesen zu Beginn des 15. Jahrhunderts auf. Für die Unterwerfung der Burggrafen von Dohna benötigte Markgraf Wilhelm I. 1401/02 ein gut gerüstetes Heer, wofür er seine osterländischen Neffen Friedrich IV. und Wilhelm II. um Unterstützung bat. Wilhelm II. hielt sich persönlich bei den Truppen seines Onkels auf. Möglicherweise führte er eine Abteilung Fußknechte des Lutz von Varnrode, der den Osterländern erst am 22. Mai 1402 zugesagt hatte mynen hernn funfczen mit glevien fueren sal uff synen schaden unde uff myner hern koste virczen tage. 10 Auch wenn im Detail nicht eindeutig, handelte es sich bei den fünfzehn Männern vermutlich um Berittene, deren Hauptbewaffnung die Gleve, eine Stangenwaffe, darstellte. Varnrode übernahm für zwei Wochen den Unterhalt dieser Männer. Sollten sie verletzt werden oder ihre Pferde und Ausrüstung zu Schaden kommen, waren hierfür jedoch Friedrich IV. und Wilhelm II. verantwortlich und mussten Schadensersatz zahlen.

Abkommen wie diese markieren bereits einen Übergang vom Lehns- zum Söldnerheer, denn es ist nicht sicher gesagt, dass die fünfzehn Männer tatsächlich dienstabhängige Knechte des Lutz von Varnrode gewesen sind. Möglicherweise handelte es sich bei ihnen bereits um geworbene Söldner.

Ergänzt wurde das Heer des Markgrafen durch Aufgebote der meißnischen Städte. Die Wettiner hatten ihren Landesausbau im Hochmittelalter vor allem durch eine intensive Stadtgründertätigkeit betrieben. Die Bürgerschaft der Städte hatte das Recht, Waffen zu führen, woraus im Bedarfsfall aber auch eine Verpflichtung werden konnte, die Kriegsbemühungen der Landesherren durch eigene Aufgebote zu unterstützen. In dem Heer, mit welchem Markgraf Wilhelm I. 1402 die Burg Dohna belagerte, befanden sich auch Aufgebote der Städte Dresden und

8 Vgl. Kroener, Kriegswesen (wie Anm. 5), S. 2 f.

9 Hierzu: Malte Prietzel, Kriegführung im Mittelalter. Handlungen, Erinnerungen, Bedeutungen (Krieg in der Geschichte 32), Paderborn u. a. 2006; MARcel Dorfer, Vom Niedergang der feudalen Heeresverfassung zum Militärwesen der frühen Neuzeit, in: Thomas Konberger/Ilja Steffelbauer (Hg.), Krieg in der europäischen Neuzeit, Wien 2010, S. 13-35.

10 Hubert Ermisch (Hg.), Die Urkunden der Markgrafen von Meißen und Landgrafen von Thüringen 1396-1406 (Codex Diplomaticus Saxoniae Regiae I/B/2), Leipzig 1902 (im Folgenden: CDS I/B/2), Nr. 429, S. 290. 
Leipzig. Die Dresdner hatten dafür eine „gedeckte Angriffsmaschine“,"11 vermutlich einen Mauerbrecher, gebaut. Der Markgraf brachte zwei große Steinbüchsen mit ins Feld, ebenso die Stadt Dresden. Eine weitere steuerte die Stadt Freiberg bei. Von hier kam vermutlich auch eine Handvoll „Steinbrecher“, die für die Herstellung der Kugeln angeworben wurden. Dass eine größere Anzahl Bergleute zum Unterminieren der Burgmauern hinzugezogen wurde, wie spätere Geschichtsschreiber behaupten, lässt sich hingegen nicht belegen. ${ }^{12}$

Die Vielzahl an Fehden und begrenzten militärischen Auseinandersetzungen zu Beginn des 15. Jahrhunderts führte dazu, dass die Wettiner immer wieder kleinere Truppen ins Feld stellten, die sich vor allem aus den hier beschriebenen Aufgeboten von Adligen oder den Truppenkontingenten der Städte rekrutierten. Doch mit dem Ausbruch der Hussitenkriege 1419 veränderte sich die Art der Kriegsführung in Mitteleuropa auf drastische Weise. Nicht nur die zahlenmäßige Stärke der Truppen wuchs nun erheblich an, auf dem Schlachtfeld spielten sich zudem dramatische taktische Veränderungen ab.

Am 12. Juni 1420 erschien ein von König Sigismund zusammenberufenes Kreuzfahrerheer vor Prag und schlug sein Lager im Tiergarten auf. Der Beitrag Friedrichs IV. zu diesem Kreuzzug bestand vermutlich aus ca. 500 Rittern nebst einigem Fußvolk, das die Städte aufbrachten. Diese Zahlen lassen sich allerdings nur rückwirkend rekonstruieren. Am 30. Dezember 1420 bat Sigismund den Markgrafen nämlich von Brüx aus uns noch von neues mit funfhundert mannen und so vil pferden sechs monet uff sine costen dienen und helffen sol gen unsen finden. ${ }^{13}$ Diese fünfhundert Reiter waren es dann auch, die am 14. Juli den berühmten, aber erfolglosen Angriff auf den Veitsberg durchführten, den Markgraf Friedrich IV. persönlich anführte. ${ }^{14}$ Nach der verheerenden Niederlage zog sich das Kreuzfahrerheer von Prag zurück und löste sich regelrecht auf.15

11 Vgl. Rainer Gross, Dresden im 15. Jahrhundert, in: Dresdner Hefte 65 (2001), S. 7982, hier S. $79 \mathrm{f}$.

12 Vgl. Oтto Mörtzsch, Des Schlosses Dohna Fall und Ende, in: NASG 37 (1916), S. 135-141, hier S. 135 f.

13 Hans Beschorner (Hg.), Die Urkunden der Markgrafen von Meißen und Landgrafen von Thüringen 1419-1427 (Codex Diplomaticus Saxoniae Regiae I/B/4), Leipzig/ Dresden 1941 (im Folgenden: CDS I/B/4), Nr. 113, S. 71.

14 Vgl. Jan Durdík, Hussitisches Heerwesen, Berlin 1961; Františex Šmahel, Die Hussitische Revolution, 3 Bände (Monumenta Germaniae Historica, Schriften 43), Hannover 2002; Ferdinand Seibt, Vom Vítkov bis zum Vyšehrad. Der Kampf um die böhmische Krone 1420 im Licht der Prager Propaganda, in: Ders., Hussitenstudien. Personen, Ereignisse, Ideen einer frühen Revolution (Veröffentlichungen des Collegium Carolinum 60), München 21991, S. 185-207, hier S. 185-187.

15 Vgl. Františse Palackŕ, Geschichte von Böhmen. Größtentheils nach Urkunden und Handschriften, Bd. 3, Abt. 2: Der Hussitenkrieg, von 1419-1431, Prag 1851, S. 131-133; Šmahel, Hussitische Revolution II (wie Anm. 14), S. 1094; Durdík, Hussitisches Heerwesen (wie Anm. 14), S. 205 f.; SeIBt, Vom Vítkov bis zum Vyšehrad (wie Anm. 14), S. 187-196. 
Das meißnische Heer während der Hussitenkriege bestand zu einem Teil aus lehnspflichtigen Adligen des wettinischen Herrschaftsbereiches. Dies geht aus einer Reihe von Belehnungen dieser Zeit deutlich hervor. Am 20. Januar 1420 belehnte Markgraf Friedrich IV. den Vogt von Zörbig, Protz von Querfurt, für drei Jahre mit dem dortigen Vorwerk, den Zöllen und den Gerichten. Dafür sollte Querfurt auf seiner Vogtei zcu synem satile funff pferde uff zcwen glefenigen, acht pferde uff vier glefenigen und vir redliche gewapnete schuczczenen, das machet an der zcal sebenczien pferde ${ }^{16}$ unterhalten. In ähnlichem Sinne wurde am 17. März 1422 ein Sühneabkommen zwischen den drei wettinischen Markgrafen und den Brüdern Erasmus, Fritz, Heinz, Michel und Hermann von Streitberg geschlossen. Darin verpflichteten sich die Brüder, den Markgrafen mit 20 Gleven zu Diensten zu sein. Allerdings beschränkte sich ihre Dienstpflicht auf gerade einmal zwölf Tage ${ }^{17}$ und entsprach damit noch einem klassischen Lehnsdienst.

Für die für den Feldzug 1421 von Friedrich IV. geforderten Kriegsdienste und die Stellung von 500 Berittenen war König Sigismund bereit, 30000 Gulden zu zahlen. ${ }^{18}$ In einem separaten Abkommen wurde geregelt, dass der König zusätzlich für die entstehenden Schäden an Männern, Pferden und Ausrüstung aufkommen werde. Dafür würden ihm die meißnischen Ritter alle ihre Gefangenen überantworten. ${ }^{19}$ Einen gleichen Brief erhielt Wilhelm II. am 6. Januar 1421 in Aussig. Auch er sollte demzufolge funfhundert Mannen und pferden ${ }^{20}$ nach Böhmen schicken. Friedrich und Wilhelm wurden durch diese Vereinbarungen selbst zu Söldnerführern, die ihre wie auch immer rekrutierten Streitkräfte gegen Geld einem höher gestellten Fürsten vermieteten. Damit begann im meißnisch-sächsischen Raum auf höchster Ebene das, was Bernhard Kroener als „Versöldnerung des Lehnsrittertums“ bezeichnete. Da die herkömmlichen Lehnsaufgebote mit ihrer zeitlich begrenzten Dienstpflicht den Ansprüchen moderner Kriegsführung nicht mehr genügten, wurden sie als Grundlage einer neuen, vertraglich vereinbarten und durch Geldzahlungen oder Verpfändungen vergütete Kriegsdienstverpflichtung genutzt. ${ }^{21}$

Nachdem auch der Zweite Hussitenkreuzzug im Herbst 1422 scheiterte, hatte der Dritte Kreuzzug im Jahr 1423 bereits nur noch den Charakter einer Entsatzaktion für die von den Hussiten bedrängte Burg Karlstein. Friedrich IV. unternahm weiterhin große Anstrengungen, um ein Heer für die neue Feldzugsaison aufzustellen. Diese Bemühungen kamen allerdings nur sehr langsam voran. Der Markgraf hatte große Probleme, die Reihen seines Heeres zu füllen. So berichtete der Bischof von Würzburg am 29. September 1422, wie unsere beere die Marg-

16 CDS I/B/4 (wie Anm. 13), Nr. 176, S. 107 f.

17 Vgl. ebd., Nr. 181, S. 109 f.

18 Vgl. ebd., Nr. 113, S. 71.

19 Vgl. ebd., Nr. 114, S. 71 f.

20 Frantisek PalackÝ, Urkundliche Beiträge zur Geschichte des Hussitenkrieges vom Jahre 1419 an, Prag 1873, Bd. 1, Nr. 56, S. 56.

21 Vgl. Kroener, Kriegswesen (wie Anm. 5), S. 5. 
graue von Missen nicht fil Volks gewynne, so versten wir auch sust wol, dasz sie von Reysigen zewge nicht seer stark werden, als sie dann bie disseyd waldes nymand geworben haben, wiewohl derselben viel gerne mit jn geritten weren. ${ }^{22}$ Und schon am zweiten Oktober sprach sich der Bischof dafür aus, So man vmb Nuremberg verstunde und sebe, dasz dis Zugk nit trefflich furgeben wurde, dasz dann besser were, man kerte in der Zyt hie awssen umb, denn dortynnen. ${ }^{23}$ Die Kritik des Bischofs, dass Friedrich niemanden „geworben“ habe, obwohl dies ohne Weiteres möglich gewesen wäre, impliziert, dass es ein großes Potenzial an Söldnern gab und dieses von vielen Reichsfürsten bereits genutzt wurde, um ihre Heere aufzufüllen. Es ist jedoch auch denkbar, dass die Verfügbarkeit von Söldnern nicht so hoch war, wie der Bischof es schilderte. Die Nachfrage nach Söldnern war zu Beginn der 1420er-Jahre enorm hoch. Viele Reichsstände warben Truppen für die Kreuzzüge gegen die Hussiten, an der Ostsee war der Krieg zwischen Polen und dem Deutschen Orden neu entbrannt und in Frankreich wütete der Hundertjährige Krieg. Es erscheint daher nur wahrscheinlich, dass eine gewisse Verknappung auf dem Söldnermarkt eintrat.

Von einer möglichen Skepsis des mittlerweile zum Kurfürsten erhobenen Friedrich gegenüber diesem neuen Kriegertypus kann keine Rede sein. Die Gefahr, die von den Hussiten für die nordböhmischen Besitzungen des Kurfürsten ausging, war insbesondere nach der Niederlage von Aussig 1426 sehr groß. Am 16. November desselben Jahres übertrugen Friedrich I. und Landgraf Friedrich der Friedfertige Schloss und Vogtei Riesenburg für ein Jahr an Gelfriede von Trachenfels. Dieser war nun verpflichtet, das er nunczig menschen redelicher menre uf demselbin unserm sloße tegelich by ym halden und haben sal. ${ }^{24}$ Dafür erhielt Trachenfels 1500 Gulden, von denen 1000 aus der Kasse des Kurfürsten kamen. Mit diesem Geld sollte auch der Unterhalt und die Verpflegung der 90 Söldner beglichen werden. Sollte die Zahl der Besatzung auf über 90 Mann steigen, so mussten der Kurfürst und der Landgraf dafür zusätzliche Mittel bereitstellen. Dieser Vertrag ist insofern beachtlich, da hierin erstmals ein befestigter Platz nicht durch einen Pfandvertrag vergeben oder nach klassischem Lehnrecht einem sächsischen Adligen übertragen wurde, sondern ein spätmittelalterlicher Söldner für einen begrenzten Zeitraum mit seinem militärischen Schutz beauftragt und dafür bezahlt wurde.

Generell ist davon auszugehen, dass die wettinischen Heeraufgebote während der Hussitenkriege wohl eine Mischform zwischen traditionellen Lehnsaufgeboten und Söldnerheeren darstellten. Formell waren die meißnischen Lehnsträger den Wettinern zur Heerfolge verpflichtet, ebenso wie diese selbst dem König. Doch bereits die Verträge Friedrichs mit Sigismund belegen, dass der Markgraf sich seine Gefolgschaft finanziell vergüten ließ. Auf der anderen Seite heuerten die

22 PalackÝ, Urkundliche Beiträge I (wie Anm. 20), Nr. 213, S. 239.

23 Ebd., Nr. 214, S. 241.

24 Vgl. CDS I/B/4 (wie Anm. 13), Nr. 557, S. 359. 
markgräflichen Lehnsleute wohl vermehrt Söldner an, um ihrer Pflicht zur Heerfolge nachzukommen.

Doch nicht nur in Hinblick auf ihre soziale Zusammensetzung brachten die Hussitenkriege große Veränderungen mit sich. Auch die taktische Zusammensetzung der Heere änderte sich zunehmend. In Westeuropa hatte das 14. Jahrhundert bereits das erlebt, was einige anglikanische Militärhistoriker als die „Revolution der Infanterie“ bezeichneten. 1386 schlugen Schweizer Knechte in dicht gedrängten Haufen mit langen Spießen ein habsburgisches Ritterheer in der Schlacht bei Sempach. Bereits 1314 vernichteten die schottischen „skildrons“ - Formationen aus mit langen Piken bewaffneten Fußtruppen - ein englisches Reiterheer in der Schlacht bei Bannockburn. 1346 scheiterte ein Kavallerieangriff französischer Ritter bei Crécy im Pfeilhagel englischer Langbogenschützen, ein Desaster, welches sich 1419 bei Azincourt wiederholen sollte. ${ }^{25}$

Auch die Heere der Hussiten setzten auf die Kampfkraft des Fußvolks, weil den „böhmischen Ketzern“ das Geld für die Ausrüstung zahlenmäßig starker Ritterheere fehlte. Da der Langspieß in Mitteleuropa zu dieser Zeit noch wenig verbreitet war, führten die böhmischen Truppen vor allem kurzstielige Stangenwaffen, wie Helmbarten, Gleven und Aalspieße, oder Distanzwaffen wie Armbrüste und Stabbüchsen. Zur Abwehr von Reiterangriffen verließen sie sich nicht allein auf die Standhaftigkeit dichter Formationen, sondern errichteten Wagenburgen, an denen die Attacken der Kreuzritter zerschellten. Erst dann, als die Angriffswucht gebrochen war, gingen sie zum Gegenangriff über. Deswegen kann im böhmischen Fall wohl nur begrenzt von einer Revolution der Infanterie gesprochen werden, waren doch die Fußtruppen stets auf den Schutz der Wagenburg angewiesen. Dennoch erwies sich diese Taktik als so erfolgreich, dass die Hussiten anderthalb Jahrzehnte allen Invasionsversuchen widerstanden. Den beeindruckendsten Erfolg errangen die Böhmen mit ihrer Wagenburgtaktik 1426 über ein sächsisches Heer, welches zum Entsatz der Stadt Aussig ausgezogen war. ${ }^{26}$

Auch im meißnisch-sächsischen Raum gewann das Fußvolk immer mehr an taktischer Bedeutung. Für dessen Bereitstellung spielten vor allem die städtischen Aufgebote eine große Rolle. Als wichtige Handels- und Wirtschaftszentren waren

25 Vgl. Kroener, Kriegswesen (wie Anm. 5), S. 4, 8.

26 Zur Schlacht bei Außig: Hubert Ermisch, Zur Geschichte der Schlacht bei Außig, in: NASG 47 (1926), S. 5-45; Alexander Querengësser, Triumph for the heretics. The Battle of Außig 1426, in: Medieval Warfare 2 (2015), S. 42-46. Zum Heerwesen der Hussiten: Kroener, Kriegswesen (wie Anm. 5), S. 10-12; Uwe Tresp, Böhmen als Söldnermarkt des ausgehenden Mittelalters, in: Thomas Kolnberger/Ilja Steffelbauer (Hg.), Krieg in der europäischen Neuzeit, Wien 2010, S. 36-57, hier S. 40-43; Ders., Die "Quelle der Kriegsmacht“. Böhmen als spätmittelalterlicher Söldnermarkt, in: Stig Förster/Christian Jansen/Günther Kronenbitter (Hg.), Rückkehr der Condottieri? Krieg und Militär zwischen staatlichem Monopol und Privatisierung: Von der Antike bis zur Gegenwart (Krieg in der Geschichte 57), Paderborn u. a. 2010, S. 43-61; Alexander Querengässer, Die Heere der Hussiten, Teil 1: Ausrüstung, Organisation, Einsatz (Heere \& Waffen 25), Berlin 2015. 
Städte in der Lage, die nötigen finanziellen Mittel zu akquirieren, um eine größere Anzahl an Fußknechten auszurüsten und zu besolden oder durch die eigene wehrpflichtige Bevölkerung selbst zu stellen. ${ }^{27}$ Aber auch die Konzentration fähiger Handwerker ließ den städtischen Aufgeboten einige Bedeutung zukommen. Beispielsweise ließ Friedrich IV. dem Rat von Dresden im Juni 1422 mitteilen, dass er seinem Aufgebot auch acht Zimmerleute mit Werkzeugen beigeben solle. ${ }^{28}$ Diese wurden vermutlich zur Errichtung von Feldbefestigungen und für Belagerungen benötigt, die im spätmittelalterlichen Kriegsalltag wesentlich mehr Zeit beanspruchten als Schlachten.

Im Urkundenbestand der Stadt Leipzig sind etliche Briefe überliefert, die die Bedeutung des städtischen Aufgebots für die wettinische Kriegsführung ansprechend unterstreichen. Bereits Ende Januar 1426 forderte Kurfürst Friedrich vom Rat der Stadt, ein Aufgebot nach Aussig zu schicken, da die dortigen Kommandeure dem Vogt zu Meißen bereits eindringliche Warnungen hatten zukommen lassen, wonach sich die hussitischen Heere dem Norden Böhmens näherten. ${ }^{29} \mathrm{Am}$ 10. Februar meldeten die Kommandeure der Stadt an die sächsische Kurfürstin, das sich dy Weißen nu an deßem nesten fritage der haben vom Slan vnde czyben vff Lunde, onde vns eygentliche botschaft kummen ist, daz sy vor ons ond ons berynnen vnd belegen wullen czu der Aswig in dryen tagen, vnde dy von Lutenbritz unde Sacz vnd andern eren steten iczlicher stat dy helffte vff geboten ist, dy iczczunt alle czu czyben onde sammeln sich by Lune. ${ }^{30}$ Katharina forderte daher den Leipziger Rat nochmals auf, die bereits zugesagten 40 Schützen umgehend nach Pirna zu schicken. ${ }^{31}$

Als der Kurfürst nach der Niederlage des Entsatzheeres nach Sachsen zurückkehrte, dachte er nicht an Verteidigung, sondern bereits wieder an den Angriff, immerhin hielt die Stadt Brüx der hussitischen Belagerung weiterhin stand. Mit leichtem Unmut schickte er der Stadt Leipzig die Überlebenden ihres Aufgebots zurück und beklagte sich, dass sie eczwaß unrustig und unwerbaft synt. ${ }^{32}$ Der Kurfürst wies darauf hin, dass er das städtische Aufgebot bald wieder zu den Waffen rufen werde und forderte den Rat nun auf, das ir uns denne redliche und werhafftige lute sendet, wenne ir selber wol irkennet, das es not tut. ${ }^{33}$ Aus diesen Worten wird deutlich, dass auch Friedrich nach dem Fall von Aussig mit einer hussitischen Invasion rechnete.

27 Vgl. Kroener, Kriegswesen (wie Anm. 5), S. 3-6.

28 Vgl. CDS I/B/4 (wie Anm. 13), Nr. 197, S. 117.

29 Ebd., Nr. 474, S. 313 enthält das Schreiben der Kommandeure an den Vogt zu Meißen; Nr. 475, S. 314 die Forderung Friedrichs an den Rat der Stadt Leipzig.

30 Karl Friedrich von Posern-Klett (Hg.), Urkundenbuch der Stadt Leipzig (Codex diplomaticus Saxoniae regiae II/8), Leipzig 1868 (im Folgenden: CDS II/8), Nr. 142, S. 95.

31 Vgl. CDS I/B/4 (wie Anm. 13), Nr. 482, S. 318 f.

32 Ebd., Nr. 520, S. 336.

33 Ebd. 
Nach dem großen Hussiteneinfall 1429/30 wurden die Bewegungen böhmischer Heere an der Grenze noch kritischer beäugt. Im Juni 1430 forderte Burggraf Heinrich von Meißen von der Stadt Dresden andirbalb bundert adir czweibundert manne werlicher adir so ir konet meist konnet geriten und zu fuße und dii auf den nest komenden mantag mit dem tage zu Reynhartzgrymme habet mit hantbuchsen und armbrusten und iren besten weren, und speise mit yn nebmen. ${ }^{34} \mathrm{Zweihun}^{\mathrm{K}}$ dert Mann stellten ein durchaus beachtliches Aufgebot dar, sie dienten jedoch der unmittelbaren Landesverteidigung. Für einen Kriegszug nach Magdeburg forderte Kurfürst Friedrich II. 1435 lediglich 50 Mann mit Wagen, Büchsen und Armbrüsten von der Stadt. ${ }^{35}$ Freiberg stellte für den Feldzug nach Böhmen 1426 allerdings sogar 300 Mann, von denen 200 in der Schlacht bei Aussig umgekommen sein sollen. Während des Sächsischen Bruderkrieges zogen 1447 wiederum 200 Freiberger nach Thüringen. ${ }^{36}$ Das zu dieser Zeit noch wesentlich kleinere Wittenberg stellte in diesem Krieg ebenfalls mehrfach ein Aufgebot zur Verfügung, von denen das kleinste nur 5 Berittene und 18 Fußsoldaten mit drei Wagen, das größte immerhin 10 Berittene, 74 Fußsoldaten und 12 Wagen umfasste. ${ }^{37}$

Neben den Städten waren auch die Ämter zur Stellung von Heerwagen und Mannschaften verpflichtet. Jens Kunze hat in seiner Studie über das Amt Leisnig auch die Pflicht zur Heerfolge untersucht. Gesichert ist, dass das Amt eigene Heerwagen stellte. Inwiefern die bäuerliche Bevölkerung der Dörfer zum Dienst herangezogen wurde, lässt sich dagegen nicht sicher klären. Möglicherweise dienten sie nur als Knechte für die Heerwagen oder als Schanzarbeiter bei Belagerungen..$^{38}$

Im weiteren Verlauf des 15. Jahrhunderts gewannen Söldner als professionelle Berufskrieger immer mehr Bedeutung für das sächsische Kriegswesen, spätestens nachdem die Stände den sächsischen Herzögen im April 1437 in Zwickau das Versprechen abgerungen hatten, das Landesaufgebot nur noch zur Landesverteidigung zu nutzen. ${ }^{39}$ Für seinen Heerzug nach Soest 1447 warb Herzog Wilhelm III. allein 6000 böhmische Söldner an. ${ }^{40}$

34 Karl Friedrich von Posern-Klett (Hg.), Urkundenbuch der Städte Dresden und Pirna (Codex diplomaticus Saxoniae regiae II/5), Leipzig 1875 (im Folgenden: CDS II/5), Nr. 181, S. 149.

35 Vgl. ebd., Nr. 196, S. 161 f.

36 Vgl. Отто Mörtzsch, Das wehrhafte Freiberg im Mittelalter, in: Zeitschrift für historische Waffen- und Kostümkunde 7 (1915-1917), S. 216-224, hier S. 223.

37 Vgl. Herbert Kосн, Wittenberger im Sächsischen Bruderkriege 1446/51, in: ebd. 5 (1909-1911), S. 126 f., hier S. 126.

38 Vgl. Jens Kunze, Das Amt Leisnig im 15. Jahrhundert. Verfassung, Wirtschaft, Alltag (Schriften zur sächsischen Geschichte und Volkskunde 21), Leipzig 2007, S. 144-153.

39 Vgl. Uwe Tresp, „mit der hilff gots und anderer unnserer heren und frunde“. Das sächsische Heer zur Verteidigung Luxemburgs gegen Burgund (1442-1444) als Instrument wettinischer Westpolitik, in: Sascha Bütow/Uwe Riedel/Uwe Tresp (Hg.), Das Mittelalter endet gestern. Beiträge zu Landes- Kultur- und Ordensgeschichte. HeinzDieter Heimann zum 65. Geburtstag (Studien zur brandenburgischen und vergleichenden Landesgeschichte 16), Berlin 2014, S. 121-143, hier S. 129.

40 Hierzu: Adolph Bachmann, Herzog Wilhelm von Sachsen und sein böhmisches Söldnerheer auf dem Zuge vor Soest, in: NASG 2 (1881), S. 97-128; Heinz-DieTER 
Trotz dieser Zahlen blieben auch die traditionellen Lehnaufgebote, insbesondere aber die Städte mit ihrem großen Reservoir durchaus gut gerüsteter Fußtruppen von Bedeutung. So verlangte Kurfürst Friedrich II. am 1. September 1446 von der Stadt Leipzig immerhin zcwey hundert redelicher schutzen mit armbrusten und andern webren, dortzu zwo steinbuchssen..$^{41}$ Im Juli 1449 forderte er gar die Bereitstellung der Hälfte des städtischen Aufgebots mit waynen, vier steinbuchssen, buchssenmeistern, puluer und steinen dorczu gehorinde, armbrusten, hantbuchsen, spissen und flegeln in allermasse. ${ }^{42}$ Im September ordnete Friedrich jedoch an, statt dieses Aufgebots 40 Trabanten nach Delitzsch zu schicken. ${ }^{43}$ Diese Forderung ist insofern interessant, da "Trabant“ eine gängige Bezeichnung für Fußsoldaten aus Böhmen darstellte. ${ }^{44}$ Es scheint, als haben die Bürger Leipzigs sich ihrer Verpflichtung zur Heerfolge entledigt, indem sie selbst als Kriegsunternehmer für den Kurfürsten auftraten und einige Söldner für das sächsische Heer anwarben. Ganz ähnlich handhabte es wohl auch die Stadt Dresden, wie aus der Klage des Kurfürsten vom 13. Juli 1449 hervorgeht. Demnach hielt die Stadt den Sold für zwei in Brüx stationierte Trabanten zurück, die der dortige Hauptmann geworben hatte, nachdem zwei andere von der Stadt geworbene Söldner ermordet worden waren. 45

Im Zuge der Hussitenkriege war die Wagenburg zum festen Bestandteil mitteleuropäischer Kriegsführung geworden. Die hierzu benötigten Heerwagen wurden ebenfalls zum Teil durch die Städte und Ämter gestellt. So forderte Kurfürst Friedrich II. im Juni 1443 von der Stadt Dresden zusätzlich zum städtischen Aufgebot wayn pferden und allen sachen zcur were und waynburg. ${ }^{46}$ Auch die Unterbringung der Truppen im Feld mit Zelten wurde wohl teilweise von den Städten übernommen. Zumindest verlangte Herzog Albrecht 1490 vom Amtmann der Stadt Freiberg die Aufstellung eines wohl gerüsteten Aufgebots mit wagen, gezelten und aller ander nottorffe..$^{47}$

Während Städte Wagen und Fußvolk stellten, spielten bei den geworbenen Söldnern zur Mitte des Jahrhunderts Berittene immer noch eine große Rolle. So schloss Friedrich II. am 7. August 1450 mit einem Jungol Tossen und anderen Söldnerführern einen Vertrag zur Stellung von 60 Reisigen zu Pferd ab, die pro Woche

Heimann/Uwe Tresp (Hg.), Thüringische und böhmische Söldner in der Soester Fehde. Quellen zum landesherrlichen Militärwesen im 15. Jahrhundert aus thüringischen und sächsischen Archiven, Potsdam 2002; Uwe Tresp, Ein Beispiel für Anwerbung, Kosten und Rechtspraxis böhmischer Söldnerheere in der Mitte des 15. Jahrhunderts. Die böhmischen Söldner Herzog Wilhelms III. von Sachsen, in: Mediaevalia Historica Bohemica 8 (2001), S. 169-201.

41 CDS II/8 (wie Anm. 30), Nr. 241, S. 186.

42 Ebd., Nr. 256, S. 195.

43 Ebd., Nr. 261, S. 197.

44 Tresp, Böhmen als Söldnermarkt (wie Anm. 26), S. 43.

45 Vgl. CDS II/5 (wie Anm. 34), Nr. 239, S. 184.

46 Ebd., Nr. 223, S. 176.

47 Sächsisches Staatsarchiv - Hauptstaatsarchiv Dresden (im Folgenden: HStA Dresden), 10024 Geheimer Rat, Loc. 9083/6: Kriegs-Sachen 1450-1611, fol. 17. 
20 Groschen erhalten sollten. Die Verpflegung der Truppen und den eventuellen Schadensersatz übernahm der Kurfürst. ${ }^{48}$

Auch die von Wilhelm III. für die Soester Fehde angeworbenen böhmischen Aufgebote bestanden aus etwa gleich viel Berittenen wie Fußtruppen. Die genauen Zahlen lassen sich zwar nicht ermitteln, allerdings gehen Heinz-Dieter Heimann und Uwe Tresp von 3921 bis 4062 Pferden und 2573 bis 2635 Trabanten aus. Da von der Zahl der Pferde die Anzahl der Zugtiere für die Heerwagen abgezogen werden muss - etwa 1200 Pferde für 300 Wagen -, standen etwa 2800 Reiter 2600 Mann Fußtruppen gegenüber. ${ }^{49}$ Dieses Verhältnis spiegelt sich auch in den meisten Einzelaufgeboten wieder. Nur wenige wiesen stärkere Schwankungen auf. So führte Jan von Mosnova zu Buchlow 145 Reiter und nur 7 Trabanten ins Feld, Jan Kerunk von Lom dagegen 25 Pferde und 104 Trabanten. Das stärkste Einzelkontingent stellte Jan Calta von Kamenná Hora zu Rabstejn. Er stellte Wilhelm insgesamt 630 Reiter, 200 Wagenpferde (50 Wagen) und 576 Trabanten zur Verfügung. ${ }^{50}$

Obwohl Söldner im 15. Jahrhundert zur dominierenden Kraft auf den Schlachtfeldern wurden und Historiker bereits von einem „Zeitalter der Söldner“ sprechen, stellten die Heere der Wettiner in dieser gesamten Zeit eine Mischform aus angeheuerten Berufssoldaten und klassischem Lehnsaufgebot dar. Noch 1482 teilten Kurfürst Ernst und Herzog Albrecht der Äbtissin des Nonnenklosters in Frankenhausen mit: wenn wir euch anderweit schreiben [...], so uns dann andere closter in unsern landen gelegen uff unsern anfordern zu solchem mit pferd und wagen gedynet. ${ }^{11}$ Das Schreiben impliziert, dass noch weitere, wenn nicht sogar alle sächsischen Klöster zu diesem Zeitpunkt noch zur traditionellen Heerfolge verpflichtet waren. Wenige Jahre zuvor (1474) hatten Ernst und Albrecht von sämtlichen sächsischen Städten eine Auflistung der zur Heerfolge stellbaren Reisigen, Wagen, Fußknechte und Büchsen gefordert, 52 was verdeutlicht, dass diese zumindest in den Planungen der Landesfürsten eine große Rolle spielten.

Auf dem Schlachtfeld dominierte jedoch zusehends der Söldner. Im ausgehenden 15. Jahrhundert wurden die böhmischen Trabanten vermehrt vom deutschen Landsknecht abgelöst. Dieser kämpfte mit dem Langspieß in dichtgedrängten Gewalthaufen. Vermutlich war es König Maximilian, der in den Burgunderkriegen Erfahrungen mit Schweizer Reisläufern gemacht hatte und diesen Typus des Fußsoldaten dann auch im Reich einsetzte. ${ }^{53}$

Im Zuge dieses Krieges, der 1477 nach dem Tod des letzten Burgunderherzogs, Karl dem Kühnen, um die Aufteilung des burgundischen Erbes entbrannte, wurde

48 Ebd., fol. 1.

49 Vgl. Heimann/Tresp, Thüringische und böhmische Söldner (wie Anm. 39), S. 13.

50 Vgl. ebd., S. $11 \mathrm{f}$.

51 Gustav Adolph Frost, Zum Heeresdienst der sächsischen Klöster, in: NASG 39 (1918), S. 138 f., hier S. 139.

52 Hubert Ermisch, Zur Statistik der sächsischen Städte im Jahre 1474, in: NASG 11 (1890), S. 145-153, hier S. 145.

53 Vgl. Kroener, Kriegswesen (wie Anm. 5), S. 23-25. 
Herzog Albrecht von Sachsen 1488 von Maximilian als Statthalter in den Niederlanden und später als Gubernator von Ostfriesland eingesetzt. ${ }^{54}$ Für die lang anhaltenden militärischen Auseinandersetzungen mit den friesischen Ständen warb Albrecht in großem Umfang Landsknechte an. Dies tat er nicht nur als Landesfürst, sondern als Kriegsunternehmer, denn der König hatte ihn 1488 auch zu seinem Obersten Hauptmann mit einem Salär von zunächst 10000 , ab 1490 sogar 35000 Gulden ernannt. Allerdings reichten diese Summen bei Weitem nicht aus, um die enormen Kosten für die von Albrecht geworbenen Landsknechte auch nur annähernd zu decken. ${ }^{5}$

\section{Das Aufkommen des Geschützwesens}

Geschützmeister lassen sich im wettinischen Herrschaftsbereich bereits im ausgehenden 14. Jahrhundert nachweisen. Am 15. Mai 1388 verschrieb Landgraf Balthasar einem Geschützmeister namens Martin (Mertin) in Gotha jährlich drei Zentner Kupfer aus dem Zehnten des Sangerhausener Bergwerks. ${ }^{56}$ Büchsenmeister nahmen in einigen sächsischen Städten bald eine gesonderte Stellung ein und waren teilweise auch von städtischen Abgaben befreit. ${ }^{77}$

Wie bereits erwähnt, verfügte das markgräfliche Heer, welches 1402 die Burg Dohna belagerte, bereits über einen kleinen Geschützpark. Aber auch die Verteidiger besaßen Schwarzpulverwaffen: vier Stein-, eine Taras- und drei Bleibüchsen. Bei letzteren handelte es sich vermutlich um große Hakenbüchsen. ${ }^{58}$ Diese kleinen Geschütze konnten für die Verteidigung einer Burg durchaus effektiv eingesetzt

54 Hierzu allgemein: PAul BaKs, Albrecht der Beherzte als erblicher Gubernator und Potestat Frieslands. Beweggründe und Verlauf seines friesischen „Abenteuers“, in: André Thieme (Hg.), Herzog Albrecht der Beherzte (1443-1500). Ein sächsischer Fürst im Reich und in Europa (Quellen und Materialien zur Geschichte der Wettiner 2), Köln/Weimar/Wien 2002, S. 103-141; zum Ende der friesischen Episode dann: LuDwig Schwabe, Herzog Georg, ewiger Gubernator von Friesland, in: NASG 12 (1891), S. 1-26.

55 Vgl. BaKs, Albrecht (wie Anm. 53), S. 109-129.

56 Vgl. Hubert Ermisch (Hg.), Urkunden der Markgrafen von Meißen und Landgrafen von Thüringen 1381-1395 (Codex Diplomaticus Saxoniae Regiae I/B/1), Leipzig 1899 (im Folgenden: CDS I/B/1), Nr. 255, S. 201. Zu den frühen Geschützmeistern der Wettiner im 14. Jahrhundert: Woldemar LipPERT, Schützenmeister und Geschützgießer der Wettiner im 14. Jahrhundert, in: Zeitschrift des Vereins für Thüringische Geschichte und Altertumskunde NF 9 (1893-1895), S. 365-370.

57 So forderten Kurfürst Ernst und Herzog Albrecht am 16. Juni 1476 vom Rat der Stadt Grimma den dortigen Büchsenmeister Bernhard von Abgaben zu befreien, da er bie unserm lieben hern und vater gotseligenn alleczeit frybe bi euch gesessenn hat. LUDWIG Schmidt (Hg.), Urkundenbuch der Stadt Grimma und des Klosters Nimbschen (Codex Diplomaticus Saxoniae Regiae II/15), Leipzig 1895 (im Folgenden: CDS II/15), Nr. 132, S. 88.

58 Vgl. Mörtzsch, Des Schlosses Dohna Fall (wie Anm. 12), S. 138. Eine Tarasbüchse ist eine kleinkalibrige Kanone, die auf eine feste Holzbettung (Taras = Terrasse) montiert wurde. 
werden, da sie ihre Geschosse - im Vergleich zu Katapulten - sehr zielgenau abfeuerten, wodurch Stellungen der Belagerer unter einen tödlichen Beschuss genommen werden konnten.

Neben den schweren Geschützen kamen im Laufe des 15. Jahrhunderts auch kleine, handliche Feuerwaffen auf, die von einem einzelnen Schützen gehandhabt werden konnten. Obwohl in Präzision, Feuerrate und Reichweite dem Bogen und der Armbrust zunächst noch deutlich unterlegen, begannen die frühen Handbüchsen die althergebrachten Distanzwaffen schnell zu verdrängen, da sie leicht handhabbar und vor allem billig in der Herstellung gewesen sind. Auch hier waren es wohl zunächst die Städte, die ihre Zeughäuser entsprechend aufrüsteten, wie aus dem Schriftwechsel zwischen Kurfürst Friedrich I. bzw. seiner Frau Katharina und der Stadt Leipzig im Zuge der Belagerung von Aussig 1426 hervorgeht.

Das von Friedrich Ende Januar 1426 geforderte Leipziger Aufgebot bestand aus 40 gewappneten Schützen mit 10 Handbüchsen.59 Noch von Altenburg aus hatte der Kurfürst am 21. April 1426 den Leipziger Rat aufgefordert, weitere 18 Schützen zunächst nach Pirna und von dort nach Aussig zu schicken, wo sie verbleiben sollten, bis er vom Reichstag zurückgekehrt sei. Zudem beklagte er, dass mehrere Schützen, die er im Januar angefordert hatte, bereits wieder nach Leipzig zurückgekehrt waren. ${ }^{60}$ Anscheinend hatte der Rat, der für die Besoldung der Armbrustschützen aufkommen musste, einige Männer abberufen, um Kosten zu sparen. Dies geht auch aus einem am 21. April von Kaspar Rechenberg an den Rat geschickten Brief hervor, in welchem er mitteilt, dass er das von der Stadt Leipzig nach Aussig geschickte gerete (wahrscheinlich meint er die 10 Handbüchsen) nicht ohne Genehmigung der Kurfürstin zurückschicken dürfe.61

Im Laufe des 15. Jahrhunderts gewannen Handbüchsen immer mehr an Bedeutung, aber noch bis ins frühe 16. Jahrhundert blieb auch die Armbrust bei den Fußtruppen in Gebrauch, wie es beispielsweise in der Chronik von Johann Christoph Dreyhaupt bei der Erstürmung der Stadt Halle durch ein wettinisches Söldnerheer im Jahr 1478 deutlich wird: Als der Thürmer diesen Lärm vermerkte, und deswegen beftig an die Glocke schlug; so entstund das Geschrey, der Feind habe das Ulrichsthor eingenommen. Hierauf legten manche von der Gemeine und Pfännern ibre Harnische an, versammelten sich vor dem Rathbause, liefen nach dem Ulrichsthor, und schossen mit Armbrüsten und Handbüchsen auf einander. ${ }^{62}$

59 Vgl. CDS I/B/4 (wie Anm. 13), Nr. 474, S. 313 enthält das Schreiben der Kommandeure an den Vogt zu Meißen; Nr. 475, S. 314 die Forderung Friedrichs an den Rat der Stadt Leipzig.

60 Vgl. ebd., Nr. 494, S. 323.

61 Vgl. ebd., Nr. 499, S. 325.

62 Johann Christoph von Dreyhaupt, Pagus Neletici et Nudzici, oder Ausführliche diplomatisch-historische Beschreibung des zum ehemaligen Primat und Ertz-Stifft, nunmehr aber durch den westphälischen Friedens-Schluß secularisirten Herzogthum Magdeburg gehörigen Saal-Kreyses und aller darinnen befindlichen Städte, Schlösser, Aemter, Rittergüter, adelichen Familien, Kirchen, Clöster, Pfarren und Dörffer [...], Teil 1, Halle 1749, S. 120. 
Dennoch lief die Büchse den alten Waffen sukzessive den Rang ab. So heißt es in einer Anweisung des Leipziger Rats vom 11. April 1453: Wer ein burger nufort wil werden der sal zcu vor an denm rate ein buchse gebin vor ein halb newe $\beta .{ }^{63}$ Diese Waffen konnten bereits in Leipzig selbst gefertigt werden, denn in der Anweisung heißt es des Weiteren: Item so sal der rat bestellin mit dem kuppersmede, das er eczliche buchsen mache in einer grose zcu halbin schocken, dy man zcu om finde, wenne einer burger will werden. ${ }^{64}$ Der Rat machte die Modernisierung des eigenen Zeughauses also nicht vom unsicheren Zustrom neuer Bürger abhängig, sondern gab die Waffen in Auftrag, die später nur noch ausgelöst werden mussten. Das Beispiel verdeutlicht zudem, dass militärischer Bedarf auch stets der städtischen Wirtschaft förderlich gewesen ist. Nähere Aussagen, welche Wirtschaftszweige dies im Einzelnen betraf, lassen sich jedoch nur schwer treffen. In Sachsen wurden nachweislich Waffen gefertigt, wie nicht zuletzt aus der von der Stadt Grimma Mitte des 15. Jahrhunderts erlassenen Willkür für die Schmiede hervorgeht, worunter auch wachffensmyde und messersmyde fallen. ${ }^{65}$ Es kann also davon ausgegangen werden, dass Schwerter, Dolche, Stangenwaffen, Armbrüste und Handbüchsen in der Markgrafschaft bzw. dem Kurfürstentum überwiegend selbst hergestellt wurden. In Freiberg existierten seit 1380 nachweislich auch Rüstungsschmieden, die im 15. Jahrhundert wohl zu den bedeutendsten in diesem Raum gehörten. ${ }^{66}$ Für Meißen ist im Jahr 1441 ein Harnischmeister bezeugt, für Dresden ab 1475.67 $\mathrm{Zu}$ Beginn des 16. Jahrhunderts lässt sich auch ein Plattner in Wittenberg nachweisen. ${ }^{68}$

Ein Ausdruck der hohen militärischen Bedeutung, die das Geschützwesen der Wettiner bereits im frühen 15. Jahrhundert erlangt hatte, findet sich auch in der Einnahme der Mark Brandenburg durch den zum Verwalter ernannten Nürnberger Burggrafen Friedrich VI. Als Landfremder hatte Friedrich hier zunächst den Widerstand eines erstarkten Adels, allen voran der Familie von Quitzow, zu brechen. Der Chronist Engelbert Wusterwitz berichtet, wie Friedrich zunächst die Burg Freysack durch schwere Geschütze zu Fall brachte. Darnach ist er gezogen für das schloß Plane mit der großen buchse herrn Friedrichs landtgraffen in Düringen. ${ }^{69}$ Die Zuverlässigkeit der Passage ist oftmals in Zweifel gezogen wurden, da

MonTzsCH, Das wehrhafte Freiberg (wie Anm. 36), S. 220-222.

67 Отто Mörтzsch, Belehnung zweier Harnischmeister (1441 und 1475), in: Zeitschrift für historische Waffen- und Kostümkunde 6 (1912-1914), S. 175.

68 Vgl. Max von Ehrenthal, Eine sächsische Plattnerwerkstatt zu Wittenberg, in: NASG 15 (1894), S. 299-312. Otto Mörtzsch konnte für die Hussitenzeit einen Plattner im Dienst der Stadt Görlitz nachweisen, die allerdings nicht zum wettinischen Herrschaftsgebiet gehörte; Отто Mörтzsch, Preise der Waffen, Kriegsgeräte und -vorräte zur Zeit der Hussitenkriege in der Mark Meißen und der Lausitz, in: Zeitschrift für historische Waffen- und Kostümkunde 4 (1906-1908), S. 70-75, hier S. 74.

69 Wolfgang Ribbe, Die Aufzeichnungen des Engelbert Wusterwitz. Überlieferung, Edition und Interpretation einer spätmittelalterlichen Quelle zur Geschichte der Mark 
Wusterwitz' Manuskript nur durch spätere Abschriften überliefert ist. Dass sich der Burggraf das Geschütz bei Landgraf Friedrich ausgeliehen hat, findet sich nur in der Überlieferung von Peter Hafftitz. Andreas Angelus übernahm diese kleine Bemerkung nicht. Der Historiker Bernhard Rathgen ging daher davon aus, die Erwähnung des Wettiners sei eine reine Erfindung von Hafftitz gewesen, und nahm an, dass die große Bombarde, die erst in viel späteren Überlieferungen den Namen „Faule Grete“ erhielt, aus dem Haupthaus des Deutschen Ordens in Marienburg entliehen worden sei. ${ }^{70}$ Inzwischen konnte Ralf Gebuhr jedoch überzeugend nachweisen, dass es sich dabei um eine nicht haltbare Rekonstruktion des ehemaligen Generals handelte. Tatsächlich erhielt Friedrich vom Orden eine kleinere Büchse aus der Burg Schivelbin. Gebuhr geht deswegen davon aus, dass die Überlieferung durch Hafftitz korrekt ist und Friedrich das größte Geschütz für seinen Feldzug vom Landgrafen von Thüringen lieh und dann über das Wassernetz der Saale, Elbe und Havel in die Mark transportieren ließ, was auch wesentlich einfacher war, als der komplizierte Transport über fast 600 Kilometer Landweg von Marienburg her. ${ }^{71}$

Am 30. Januar 1427 nahm Kurfürst Friedrich I. einen Meister Klaus als Büchsenmeister in seine Dienste. Klaus stammte aus Gotha und ließ sich nun in Jena nieder. Detailliert regelte sein Vertrag, dass der Mester für jedes Geschütz von über zehn Zentnern Gewicht einen Gulden pro Zentner, sowie die Kosten für Knechte und Kohlen erstattet bekommen sollte. Für kleinere Stücke erhielt er nur Kupfer und Zinn, was darauf hinweist, dass diese Art von Tarasbüchßen vor allem aus Bronze gegossen und nicht im Stabringverfahren gefertigt worden sind. Zudem sollte er stets zwei Knechte unterhalten, die er bei Bedarf dem Kurfürsten zu schicken hatte. Auch er selbst konnte mit zwei oder drei Knechten zum Felddienst gerufen werden, wofür der Kurfürst die zcït futer und koste gebin wollen. ${ }^{72}$ Als Grundeinkommen wurden ihm aus der Jenaer Rente jedes Jahr zehn Schock Groschen bewilligt. Dieser Vertrag unterstreicht nochmals den großen Bedeutungsgewinn, den das Geschützwesen durch die Hussitenkriege erfahren hat.

Ein Verzeichnis aus dem Jahr 1436 listet 23 zum Herrschaftsgebiet der Wettiner gehörige Burgen und Schlösser, auf denen sich 74 Kanonen unterschiedlicher Art und 393 Handbüchsen befanden. ${ }^{73}$ Auffällig ist, dass die größten Bestände vor

Brandenburg (Einzelveröffentlichungen der Historischen Kommission zu Berlin 12), Berlin 1973, S. 144.

70 Bernhard Rathgen, Das Geschütz im Mittelalter, Berlin 1928, S. 464.

71 Vgl. Ralf Gebuhr, Technik und Repräsentation. Zum Kriegswesen der brandenburgischen Hohenzollern im 15. Jahrhundert, in: Peter Knüvener/Dirk Schumann (Hg.), Die Mark Brandenburg unter den frühen Hohenzollern. Beiträge zur Geschichte, Kunst und Architektur im 15. Jahrhundert (Schriften der Landesgeschichtlichen Vereinigung für die Mark Brandenburg, Neue Folge 5), Berlin 2015, S. 138-159, hier S. 143-145.

72 CDS I/B/4 (wie Anm. 13), Nr. 568, S. 364.

73 Отто Mörtzsch, Die Ausrüstung sächsischer und thüringischer Schlösser mit Feuerwaffen 1436, in: Zeitschrift für historische Waffen- und Kostümkunde 2 (1900-1902), S. $321 \mathrm{f}$. 
allem in den Grenzburgen konzentriert waren, namentlich in Riesenburg und Brüx jenseits des Erzgebirges, Coburg nahe den fränkischen Besitzungen der Hohenzollern und Belzig an der Grenze zur Mark Brandenburg. Zu diesem landesherrlichen Arsenal gesellten sich die Bestände der städtischen Zeughäuser. Dresden verfügte zu jener Zeit beispielsweise wenigstens über eine große Steinbüchse und zwei Tarasbüchsen, die beim Frauentor positioniert worden waren, sowie 41 Handbüchsen. ${ }^{74}$

\begin{tabular}{|l|l|}
\hline Burg & Fenerwaffenbestand \\
\hline Arnstein & 1 Steinbüchse, 6 Handbüchsen \\
\hline Königstein & 8 Handbüchsen \\
\hline Dohna & 1 Steinbüchse, 14 Handbüchsen \\
\hline Tharandt & 1 Steinbüchse, 1 Tarasbüchse, 12 Handbüchsen \\
\hline Riesenburg & 5 Steinbüchsen, 44 Handbüchsen \\
\hline Brüx & 5 Steinbüchsen, 1 Tarasbüchse, 45 Handbüchsen \\
\hline Dresden & $\begin{array}{l}\text { 1 große Tarasbüchse (wohl nur für die Burg, weitere Kanonen befanden } \\
\text { sich im städtischen Zeughaus) }\end{array}$ \\
\hline Torgau & 1 kleine Steinbüchse \\
\hline Coburg & $\begin{array}{l}\text { 8 Steinbüchsen, 2 Tarasbüchsen, 60 Armbrüste (zusätzlich werden nur hier } \\
\text { 40 Armbrüste und 100 bis 200 Pfeile gelistet) }\end{array}$ \\
\hline Saalfeld & 1 Steinbüchse, 5 Handbüchsen \\
\hline Ranis & 1 Steinbüchse von 13 Zentnern, 2 kleine Steinbüchsen, 16 Handbüchsen \\
\hline Jena & 2 Steinbüchsen, 6 Handbüchsen \\
\hline Arnshaugk & 2 Steinbüchsen, 2 Tarasbüchsen, 14 Handbüchsen \\
\hline Weida (Osterburg) & 3 Steinbüchsen, 1 Tarasbüchse, 48 Handbüchsen \\
\hline Zwickau (Osterstein) & 4 Steinbüchsen, 24 Handbüchsen \\
\hline Altenburg & 4 Steinbüchsen, 1 Tarasbüchse, 33 Handbüchsen \\
\hline Rochlitz & 3 Steinbüchsen, 14 Handbüchsen \\
\hline Leisnig (Mildenstein) & 1 Steinbüchse, 12 Handbüchsen \\
\hline $\begin{array}{l}\text { Schweinitz und Belzig } \\
\text { (Eisenhardt) }\end{array}$ & 12 Steinbüchsen \\
\hline Finsterwalde & 1 Steinbüchse, 1 Tarasbüchse, 8 Handbüchsen \\
\hline Liebenwerda & 1 Steinbüchse, 6 Handbüchsen \\
\hline
\end{tabular}

Tab. 1: Geschütze auf sächsischen Burgen im Jahr 1436

\section{Neue Arten der Befestigung}

Das Aufkommen schwerer Geschütze für Belagerungen ließ mittelalterliche Wehranlagen plötzlich veraltet erscheinen. Die hohen Mauern, die Burgen und Städte vor den Angriffen des Fußvolks und dem direkten Beschuss von Bogenschützen bewahren sollten, boten Kanonen ein hervorragendes Ziel und konnten

74 MöRtzsch, Preise der Waffen (wie Anm. 67), S. 73. 
ihnen keinen dauerhaften Widerstand leisten. Dies führte im 15. Jahrhundert zu neuen Methoden, Burgen und Städte zu befestigen.

Ein Großteil der sächsischen Städte hatte zu seinem Schutz bereits im 13. Jahrhundert Stadtmauern errichtet. 35 Ortschaften wurden im Laufe dieses Jahrhunderts befestigt, darunter Freiberg, Leipzig, Dresden und Meißen. In den nächsten 150 Jahren sollten 20 weitere folgen. ${ }^{75}$

Die Anlage von Zwingern, also der eigentlichen Stadtmauer vorgelagerte Mauern mit kleinen Bastionen, erfolgte in Mitteldeutschland wohl bereits im ausgehenden 14. Jahrhundert. Damit korrespondiert ihre Entstehung zwar mit dem Auftreten des Geschützwesens, es kann aber durchaus bezweifelt werden, dass Pulverwaffen den Grund für das Aufkommen von Zwingern darstellten. Eine Entwicklung der Verteidigungsanlagen in die Tiefe, um einen gegnerischen Angriff besser verzögern zu können, erscheint wahrscheinlicher. ${ }^{76}$

Im 15. Jahrhundert spielten schwere Geschütze dann jedoch eine entscheidende Rolle beim Wandel der Befestigungsanlagen. Aber auch die Änderungen im Herrschaftswesen führten dazu, dass Burgen als politischer, wirtschaftlicher, sozialer und militärischer Nukleus mittelalterlicher Herrschaft ihre Bedeutung verloren. Der Adel legte bei der Anlage seiner Wohnsitze zunehmend Wert auf Repräsentation, was mit den militärischen Sicherungsanforderungen einer Wehranlage oft nicht länger vereinbar war. Sichtbares Zeugnis dieses Prozesses ist die Festung „Eisenhard“ im nordsächsischen Belzig. Die Landstriche nordöstlich von Wittenberg kamen mit der Verleihung der Kurwürde und der damit einhergehenden Belehnung mit dem Herzogtum Sachsen-Wittenberg 1423 an die Wettiner. Belzig lag an der Grenze zum Kurfürstentum Brandenburg, in welchem die konkurrierenden Hohenzollern ihre Herrschaft ausbauten. Die Festung wurde 1465 von Kurfürst Ernst zur Sicherung der Grenze angelegt. Fünf gewaltige, zur Aufstellung von Kanonen geeignete Rondelle schützten die Flanken der aus roten Backsteinen errichteten polygonalen Anlage, ein Doppelturmtor den Hauptzugang zur Burg. Noch heute stellt Belzig eine Besonderheit unter den mittelalterlichen Burgen dar, denn sie ist die einzige noch weitgehend erhaltene spätgotische Festung dieser Zeit. ${ }^{77}$ Sie war zudem nicht Sitz eines Vasallen, der zur Versorgung seiner Besatzung entsprechende wirtschaftliche Nutzungsrechte im nahen Umland erhielt, sondern wurde durch einen direkt dem Kurfürsten unterstehenden Söldnerhauptmann verteidigt. Somit stellt die Burg eine rein auf militärische

75 Zahlen nach: Heinz MüLler, Betrachtungen zu den Stadtbefestigungen in Sachsen, in: Burgenforschung aus Sachsen 15/16 (2003), S. 52-73, hier S. 54 f. Müllers Zahlen beziehen sich allerdings auf das Territorium des Freistaates Sachsen. Sie beinhalten somit Städte in der Oberlausitz, die im 15. Jahrhundert nicht zum wettinischen Herrschaftsbereich gehörten, während die Besitzungen in der Landgrafschaft Thüringen und dem Herzogtum Sachsen fehlen.

76 Vgl. ebd., S. 67-69.

77 Vgl. Thomas Langer, Die Burg Eisenhardt in Belzig. Ein kursächsischer Festungsbau des 15. Jahrhunderts, in: Burgenforschung aus Sachsen 24 (2011), S. 98-138, hier S. $102-$ 127. 
Zwecke reduzierte Wehranlage, mithin die vermutlich erste sächsische Landesfestung dar.

Aber auch die Städte mussten ihre Wehranlagen modernisieren, wollten sie nicht zur leichten Beute von Heeren mit schwerer Belagerungsartillerie werden. Um den Aufprall von Kanonenkugeln abzudämpfen, wurden vor den vorhandenen Stadtmauern meist große Erdwälle aufgeschüttet. Auf diese Art und Weise konnten Stadtbefestigungen vergleichsweise kostengünstig den neuen militärischen Anforderungen angepasst werden. Als Plattform für Geschütze spielten Mauern und Wälle vorerst noch keine größere Rolle. Diese wurden in den Türmen stationiert. Obwohl sie aufgrund ihrer Baustruktur besonders anfällig für feindlichen Beschuss waren, blieben Türme während des 15. Jahrhunderts im mitteldeutschen Raum nach wie vor von großer Bedeutung für Wehranlagen. Zum einen dienten sie, wie dargelegt, als Aufstellungsort der eigenen Artillerie, zum anderen bildeten sie, nachdem die Stadtmauern bis zum Kranz mit Erde aufgeschüttet waren, eines der wenigen Bauelemente, welches noch repräsentative Zwecke erfüllen konnte. Viele hochmittelalterliche Türme wurden in dieser Zeit mit reich dekorierten Aufsätzen erhöht.

Allerdings scheinen diese baulichen Maßnahmen nicht überall in Sachsen zur Anwendung gekommen zu sein. Der Leipziger Rat investierte zwar in der Mitte des 15. Jahrhunderts umfangreiche Mittel in die Verbesserung der Stadtmauern und ließ weite Teile der Anlagen an der Wende zum 16. Jahrhundert gänzlich erneuern, ${ }^{78}$ dennoch lassen sich auf der bekannten Darstellung, die die Stadt während der Belagerung im Schmalkaldischen Krieg zeigt, der eigentlichen Stadtmauer vorgelagerte Zwingermauern erkennen, jedoch keinerlei Wallanlagen. Dagegen lässt eine Begehung der Delitzscher Stadtmauern noch heute erahnen, welche Ausmaße diese Wälle annehmen konnten. Auch wenn diese nicht mehr erhalten sind, existieren noch genügend Mauerabschnitte, vor denen mit mindestens fünf Metern Abstand ein Wassergraben angelegt ist. Dieser Abstand war vermutlich die Basis der Wallanlagen.

\section{Kriegsentscheidend: Heeresversorgung und Logistik}

Militärgeschichte - insbesondere für die Zeit des Mittelalters - war lange Zeit eine Zusammenschau von Feldzügen und Schlachten. Historiker hinterfragten die teilweise weit übertriebenen Stärkeangaben mittelalterlicher Chronisten nur selten. Wie soll König Sigismund 1421 vor Prag ein Heer von 100000 oder sogar 200000 Mann unterhalten haben, wo doch die Stadt, die er ja nicht einmal kontrollierte, selbst nur etwa 40000 Einwohner zählte? Mit den damaligen Transportmitteln

78 Vgl. Enno Bünz, Eine wehrhafte Stadt? Zur mittelalterlichen Kriegs- und Militärgeschichte Leipzigs, in: Ulrich von Hehl (Hg.), Stadt und Krieg. Leipzig in militärischen Konflikten vom Mittelalter bis ins 20. Jahrhundert (Quellen und Forschungen zur Geschichte der Stadt Leipzig 8), Leipzig 2014, S. 15-50, hier S. 33. 
konnten einem Heer nur begrenzte Mengen an Lebensmittelvorräten nachgeführt werden, weswegen es sich früher oder später aus dem Land versorgen musste. Böhmen war jedoch äußerst dünn besiedelt, und es sei daran erinnert, dass Friedrich II. im 18. Jahrhundert mehrfach Feldzüge in diesem Landstrich abbrechen musste, weil er seine - wesentlich kleineren - Truppen nicht versorgen konnte. ${ }^{79}$

Die demografische Struktur eines Landes bildete eine grundlegende Voraussetzung für die Größe des Heeres, das ein Fürst aufstellen konnte, und Faktoren wie Bevölkerungsdichte und Einwohnerzahl der größten Städte waren entscheidend für die Frage, wie viele Soldaten zu einer bestimmten Zeit an einem bestimmten Punkt konzentriert werden konnten.

Somit wird auch klar, warum Friedrich IV. die Heere, die er gegen die Hussiten ins Feld führte, stets nahe Freiberg sammelte und nicht etwa bei Dresden. Zwar bot auch der hiesige Elbkessel einen guten Sammelpunkt und der schiffbare Fluss zudem eine exzellente Versorgungsroute nach Aussig, die Stadt gehörte allerdings zum einen zum Herrschaftsbereich von Friedrichs thüringischem Vetter Friedrich dem Friedfertigen und zum anderen war sie um etwa ein Viertel kleiner als Freiberg. Zählte die Silberstadt zur Zeit der Hussitenkriege etwa 4000 bis 4200 Einwohner, so waren es in Dresden gerade einmal 3000.80

Geht man davon aus, dass Markgraf Friedrich IV. und Markgraf Wilhelm II. die jeweils 500 Reiter, die König Sigismund 1421 von ihnen forderte, tatsächlich aufbringen konnten, so folgten ihnen wohl einschließlich Fußtruppen, Knechten und Tross wenigstens 1500 bis 2000 Mann ins Feld. Dieses Heer mit seinem täglichen Lebensmittelbedarf entsprach also der Hälfte der Einwohnerschaft von Freiberg. Seine Versorgung konnte nur da sichergestellt werden, wo bereits die wirtschaftlichen Strukturen für die Ernährung entsprechend großer Menschengruppen vorhanden waren. Noch schwieriger wurden diese logistischen Probleme fünf Jahre später, denn das bei Groß-Bobritzsch (heute Oberbobritzsch) nahe Freiberg zusammengezogene Ersatzheer für Aussig umfasste etwa 8000 Ritter und Fußtruppen, zählte also zweimal so viele Menschen, wie Freiberg Einwohner hatte.

Für die Versorgung der Truppen und auch strategisch wichtiger Plätze griffen die Markgrafen anscheinend bevorzugt auf die Wirtschaftskraft der Städte zurück. Zur Verpflegung seines 1421 nach Böhmen geführten Heeres ließ Friedrich IV. Lebensmittel nach Riesenburg karren. Dies geht aus einer Anweisung an den Dresdner Rat vom 20. Januar 1421 hervor, in welcher der Markgraf befahl, vier

79 Hierzu: Olaf Groehler, Die Kriege Friedrichs II., Berlin 1968, S. 36-39, 55-59.

80 Otтo Richter, Zur Bevölkerungs- und Vermögensstatistik Dresdens im 15. Jahrhundert, in: NASG 2 (1881), S. 273-289, hier S. 282 spricht von 2593 Einwohnern im Jahr 1421 und 3956 im Jahr 1431. Zu Freiberg: Paul Knauth, Bevölkerungszahl und Bevölkerungsbewegung der Stadt Freiberg. Vom Ausgange des Mittelalters bis zur Mitte des neunzehnten Jahrhunderts, in: NASG 36 (1915), S. 300-355, hier 312 f., wobei Knauth nur eine grobe Schätzung abgeben kann. 
Wagen mit 100 Scheffel Korn bereitzuhalten. ${ }^{81}$ Die Städte verfügten über entsprechende Lebensmittelreserven, die nun für militärische Zwecke zur Verfügung gestellt werden mussten. Dies zeigte sich auch nach der Niederlage bei Aussig, als Kurfürst Friedrich I. fieberhaft an der Erneuerung seines Heeres arbeitete. Am 3. September 1426 forderte er von der Stadt Leipzig zehn gewappnete und berittene Schützen, die diese binnen einer Woche nach Freiberg zu schicken hatte. Außerdem sollte die Stadt große Mengen Getreide und Hafer liefern sowie die nötigen Fuhrleute, um selbiges nach Brüx zu überführen, welches immer noch von den Hussiten belagert wurde. ${ }^{82}$

Zwar rüsteten sowohl die Ritter der Lehnsaufgebote als auch die geheuerten Söldner sich selbst aus, dennoch musste der Landesherr in Kriegszeiten große Mengen an Kriegsgerät, aber auch Pferden bereit halten, denn in der Regel war er verpflichtet, im Kampf verloren gegangene Waffen und Tiere zu ersetzen. Besonders schwer wogen nach der Niederlage bei Aussig nicht nur die Verluste an kriegserfahrenen Rittern, sondern auch an Pferden. Dies geht aus einem Schreiben des Bischofs Georg von Gran vom 26. August 1426 hervor. Darin weist er seine Amtsleute an, für Pferde, welche der Kurfürst in Ungarn kaufen ließ, keinen Zoll zu erheben. ${ }^{83}$ Diese Tiere wurden mit hoher Wahrscheinlichkeit als Schadenersatz oder auch zur Ausrüstung des neuen Heeres, welches Friedrich aufstellen ließ, gekauft. Bezahlt wurden sie mit sächsischem Tuch, für das der Erzbischof drei Tage später ebenfalls eine zollfreie Einfuhr genehmigte. ${ }^{84}$ Dieser Handel unterstreicht die hohe Bedeutung, die das sächsische Tuchgewerbe bereits im frühen 14. Jahrhundert besessen hat.

Die Logistik scheint während des gesamten Jahrhunderts eine Domäne der heerdienstpflichtigen Städte, Klöster und Ämter geblieben zu sein. Verließen sich die sächsischen Herzöge auf dem Schlachtfeld zunehmend auf angeworbene Söldner, so hatten Städte, Klöster und Ämter immer noch die benötigten Wagen zu stellen, die diese Heere mit Lebensmitteln versorgten. Dies geht auch aus der bereits zitierten Anweisung von Ernst und Albrecht an das Nonnenkloster Frankenhausen hervor. Darin heißt es explizit, das ir [...] geschickt seit [...] solchen wagen und pferde mit sambt den knechten und andern dorzugeborende us zu richten [...] und unser und der andern gerete zu faren - dergleichen andere Köster auch getan. ${ }^{85}$ Die Kosten für die Aufbringung eines solchen Wagens betrugen einigen Angaben zufolge bis zu 300 Gulden. ${ }^{86}$ Wie viel Verpflegung einem Söldner in der Mitte des 15. Jahrhunderts zustand, erschließt sich aus den Versprechungen, die

81 Vgl. CDS I/B/4 (wie Anm. 13), Nr. 123, S. 75.

82 Vgl. ebd., Nr. 542, S. 552 f. Auch die von den Ämtern gestellten Wagen dienten wohl hauptsächlich der Versorgung; vgl.: Kunze, Das Amt Leisnig (wie Anm. 38), S. 146, 153. Vgl. CDS I/B/4 (wie Anm. 13), Nr. 540, S. 352.

84 Vgl. HStA Dresden, 10005 Hof und Zentralverwaltung, Findbuch 4.2, S. 341. Die Akte mit der Registratur-Nummer 4377/1, Ungarische Sachen, wird als fehlend verzeichnet. Frost, Zum Heeresdienst der sächsischen Klöster (wie Anm. 50), S. 139.

86 Vgl. ebd. 
Herzog Wilhelm seinen böhmischen Truppen während der Belagerung von Soest gemacht hatte. Demnach wollte er jedem Mann täglich zwei Laib Brot, Bier und Fleisch reichen. Konnten diese Mengen einen Tag nicht aufgebracht werden, so sollten die Söldner am nächsten Tag die doppelte Menge Brot und zusätzliches Bier und Fleisch erhalten. Sollte die Versorgung drei Tage hintereinander ausfallen, stand es ihnen frei zu gehen. ${ }^{87}$

Beschränkten sich die logistischen Probleme bei Lehnsaufgeboten mehrheitlich auf deren Ernährung sowie eventuellen Schadensersatz, so stellte die Aufbringung von Sold einen spätmittelalterlichen Herrschaftsverband vor große Probleme. Sowie Söldner unter Vertrag genommen waren, stand ihnen Löhnung zu, und selbst die Versorgungskosten, die sie auf ihrem Anmarsch zu den Sammelplätzen zu tragen hatten, musste der Fürst übernehmen. Diese Kosten konnten bereits sehr hoch ausfallen, weswegen es mitunter schon bei der Sammlung von Truppen zu Schwierigkeiten kommen konnte. Am 2. Juni 1447 quittierte der Söldnerführer Jindrich Cecek von Pakomerice Herzog Wilhelm III. den Empfang von 350 Gulden, mit denen die Verpflegungskosten seines Kontingents (250 Reiter, 160 Wagenpferde, 424 Trabanten) seit der Anwerbung in Eger und auf dem Marsch nach Thüringen beglichen werden sollten. ${ }^{88}$ Im Sammellager bei Weimar erhielten die Böhmen dann auch erste Soldvorschüsse. ${ }^{89} \mathrm{Da}$ diese Zahlungen die landesherrliche Kasse schnell empfindlich belasteten, versuchte Wilhelm während des Feldzuges, Gelder für künftige Soldzahlungen aufzubringen. Einbeck, das Anfang Juni 1447 von den herzoglichen Truppen besetzt wurde, sollte neben Proviant auch 10000 Gulden aufbringen, von denen 6000 sofort gezahlt werden konnten. Über die übrige Summe wurde ein Schuldschein ausgestellt. Von dieser „Kontribution“ - ganz im frühneuzeitlichen Wortsinn des Begriffes - wurde ein Großteil der am 30. Juni ausgeschütteten 8821 Gulden, 8 Groschen an Soldgeldern beglichen. 90 Unter großen finanziellen Mühen konnte Wilhelm sämtliche Sold- und Schadenersatzforderungen seiner böhmischen Truppen zahlen. Er selbst wurde jedoch herbe enttäuscht, denn er hatte gehofft, diese Kosten seinerseits durch Erzbischof Dietrich von Köln, für dessen Interessen er dieses Heer aufgestellt hatte, ersetzt zu bekommen. Dies hatte ihm Dietrich vor Soest auch persönlich zugesagt. Allerdings war der Feldzug ein Fehlschlag und die erzbischöflichen Finanzen befanden sich in einem desolaten Zustand. Wilhelm präsentierte im August 1448 seine Kriegskostenschätzung in Höhe von 242093 Gulden und 23 Groschen, von denen der Erzbischof nur einen kleinen Teil bestritten hatte, sodass er dem Herzog immer noch 230419 Gulden und 23 Groschen schuldig blieb. Wilhelm war auf die Erstattung dieser Kosten umso mehr angewiesen, da er im Zuge des kurz darauf

87 Vgl. Bachmann, Herzog Wilhelm (wie Anm. 39), S. 112; zur Verpflegung der Heeresaufgebote auch: Kunze, Das Amt Leisnig (wie Anm. 38), S. 145-147.

88 Vgl. Heimann/Tresp, Thüringische und böhmische Söldner (wie Anm. 39), S. 43.

89 Vgl. ebd., S. 14.

90 Vgl. ebd., S. 14-16; Bachmann, Herzog Wilhelm (wie Anm. 39), S. 108. 
ausbrechenden Sächsischen Bruderkrieges erneut böhmische Söldner anzuwerben gezwungen war. Eine Einigung über die Rückzahlung dieser Summe konnte zu Lebzeiten Dietrichs nicht mehr erzielt werden. Streitigkeiten über die Zahlung zumindest einer Teilsumme zogen sich zwischen den beiden Kurfürstentümern noch bis in die 1530er-Jahre. ${ }^{91}$ Um seine Söldner überhaupt bei der Stange halten zu können, sah der Herzog sich verpflichtet, ihnen die Städte und Burgen Weida, Arnshaugk, Ranis, Pösneck, Triptis, Auma und Neustadt mit allen dazugehörigen Rechten zu verpfänden. ${ }^{92}$ Solche Verpfändungen waren in der Mitte des 15. Jahrhunderts nicht unüblich, konnten sich aber für den Dienstherrn als sehr gefährlich erweisen. Auch der Deutsche Orden griff im Dreizehnjährigen Krieg (1454-1466) auf dieses Mittel zurück, um seine böhmischen und deutschen Söldner bei Laune zu halten. Zum Pfandbesitz gehörte auch das Haupthaus des Ordens, die Marienburg, die die enttäuschten Söldner 1457 schließlich dem König von Polen verkauften, womit es dem Orden unwiederbringlich verloren ging. ${ }^{93}$

Am Beispiel der Soester Fehde lassen sich bereits einige Wesensmerkmale einer Kriegsführung erkennen, die eigentlich eher dem 16. bis 18. Jahrhundert zugeschrieben werden. Die Forderungen Wilhelms an Einbeck stellen eine typische „Kontribution“ dar, mit der der Krieg sich quasi selbst ernähren sollte. Die Überstellung seines Heeres an den Kölner Erzbischof ist ein klassisches „Truppenvermietungsgeschäft" - wie man den im Zuge der Aufklärung in Verruf geratenen "Soldatenhandel“" etwas pragmatischer umschreiben sollte. Wie so viele Fürsten der Frühen Neuzeit musste auch Wilhelm erkennen, dass der Handel mit Soldaten meist ein Verlustgeschäft war.

\section{Die Entwicklung des Ständewesens im Spiegel der Heeresfinanzierung}

Mit dem Aufkommen des Söldnerwesens erhöhten sich auch die Kosten des Kriegführens im Spätmittelalter. Im Gegensatz zum lehnspflichtigen Ritter, der sich für die Zeit seines Dienstes selbst versorgen musste, erhielt der Söldner nicht nur eine Versorgung mit Lebensmitteln, sondern eben auch seinen Sold. Zwar gab es auch im Hochmittelalter noch andere Faktoren, die das Kriegführen zu einer kostspieligen Angelegenheit machten, aber diese konnten überwiegend aus den Regalien der Fürsten bestritten werden. Insbesondere die Wettiner profitierten dabei im 13. und 14. Jahrhundert vom Silberreichtum der mittel- und osterzgebir-

91 Vgl. Heimann/Tresp, Thüringische und böhmische Söldner (wie Anm. 39), S. 23-25.

92 Vgl. Bachmann, Herzog Wilhelm (wie Anm. 39), S. 116.

93 Wilhelm Rautenberg, Der Verkauf der Marienburg 1454-1457. Mit Beiträgen zum zeitgenössischen Pfand- und Herrschaftsrecht sowie zur Treuepflicht im Landrecht, in: Ernst Bahr (Hg.), Studien zur Geschichte des Preußenlandes. Festschrift für Erich Keyser zu seinem 70. Geburtstag dargebracht von Freunden und Schülern, Marburg 1963, S. 119-150. 
gischen Bergwerksstollen. ${ }^{94}$ Doch ausgerechnet im späten 14. Jahrhundert begannen diese Quellen zu versiegen.

Trotz aller Versuche konnten die Markgrafen den zunehmenden Rückgang der Fördererträge nicht stoppen. Wurden um 1350 noch jährlich etwa 2409 Kilogramm Silber gefördert, war es im Zeitraum zwischen 1390 und 1400 nur noch die Hälfte, im Durchschnitt 1276 Kilogramm. ${ }^{95}$ Dies führte dazu, dass Balthasar, Wilhelm I. und Friedrich IV. dazu übergingen, eigene Münzmeister einzustellen, um wenigstens über einen eigenständig betriebenen Münzschlag Gewinne erzielen zu können. ${ }^{96}$ Aber auch dieses Vorgehen erwies sich als nicht unproblematisch.

Markgraf Wilhelm I. beschaffte sich das Geld für sein militärisches Engagement in Brandenburg und Böhmen, indem er den Silbergehalt seiner Kreuzgroschen immer weiter reduzieren ließ. Dadurch verschlechterte sich deren Wert gegenüber dem rheinischen Goldgulden rapide. ${ }^{97}$ Friedrich IV. betrieb dagegen eine stabile Münzpolitik, was in den 1380er-Jahren vielleicht auch auf den Einfluss seiner Mutter Katharina von Henneberg zurückzuführen war. ${ }^{98}$

Die frühen Regierungsjahre Friedrichs IV. sind von einer Konsolidierung und Erweiterung seines Herrschaftsraums und seiner Finanzen geprägt. Verpfändungen von Grundbesitz oder die Verschlechterung von Münzen waren kein Mittel seiner Politik. Doch mit dem Aufflackern der Hussitenkriege nehmen die Belege für Kreditaufnahmen seitens des Markgrafen und späteren Kurfürsten zu. Diese nahm er vor allem bei den im Land ansässigen Juden auf.

Bereits im ausgehenden 14. Jahrhundert hatten die Markgrafen Juden eine Reihe von Schutzbriefen ausgestellt. ${ }^{99}$ Friedrich IV. und seinen Brüdern gelang es

94 Vgl. Ulrich Thiel, Wassernot und Strukturwandel. Zum Montanwesen im Erzgebirge und seinem Vorland in der zweiten Hälfte des 14. Jahrhunderts, in: Wilhelm der Einäugige. Markgraf von Meissen (1346-1407) (Saxonia 11), hrsg. von den Staatlichen Schlössern, Burgen und Gärten Sachsen in Zusammenarbeit mit dem Verein für Sächsische Landesgeschichte e. V., Dresden 2009, S. 67-78, hier S. 67 f.; PAul Arnold, Bergbau und Münzpolitik, in: Jutta Charlotte von Bloh/Dirk Syndram/Brigitte Streich, Mit Schwert und Kreuz zur Kurfürstenmacht. Friedrich der Streitbare, Markgraf von Meißen und Kurfürst von Sachsen (1370-1428), München/Berlin 2007, S. 26-30, hier S. 26; Uwe Schirmer, Der Freiberger Silberbergbau im Spätmittelalter (1353-1485), in: NASG 71 (2001), S. 1-26, hier S. 7-10; Johannes Langer, Die Anfänge Freibergs und seines Bergbaues, in: NASG 52 (1931), S. 1-17.

95 Zahlen nach: Thiel, Wassernot und Strukturwandel (wie Anm. 93), S. 76; vgl.: Schirmer, Freiberger Silberbergbau (wie Anm. 93), S. 16 f. Schirmer gibt an, dass sich die Ausbeute zwischen 1390/91 und 1392 schlagartig halbierte.

96 Vgl. Arnold, Bergbau und Münzpolitik (wie Anm. 93), S. 27; Schirmer, Freiberger Silberbergbau (wie Anm. 93), S. 18.

97 Vgl. Arnold, Bergbau und Münzpolitik (wie Anm. 93), S. 27; Schirmer, Freiberger Silberbergbau (wie Anm. 93), S. 18.

98 Vgl. Arnold, Bergbau und Münzpolitik (wie Anm. 93), S. 27.

99 Vgl. CDS I/B/1 (wie Anm. 55), Nr. 88, S. 61 f., Nr. 189, S. 142; Maike LÄMmerhirt, Juden in den wettinischen Herrschaftsgebieten. Recht, Verwaltung und Wirtschaft im Spätmittelalter (Veröffentlichungen der Historischen Kommission für Thüringen, Kleine Reihe 21), Köln/Weimar/Wien 2007, S. 131. 
in der Folge auch, ihre Judenpolitik gegenüber dem König durchzusetzen. Wenzel hatte 1391 alle Untertanen des Reiches von ihren Schulden bei den Juden frei gesprochen. Die osterländischen Brüder pochten jedoch auf Sonderrechte, die die Wettiner seit Langem in der Behandlung der Juden genießen würden, was Wenzel schließlich auch anerkannte. ${ }^{100}$ Am 28. Juli 1395 stellten Friedrich, seine Brüder und ihre Mutter Katharina von Henneberg einen weiteren Schutzbrief aus. Gegen die Zahlung von jährlich 250 Schock Groschen wurde allen im Land ansässigen Juden, außer jenen in der Stadt Saalfeld, für sechs Jahre Schutz gewährt. ${ }^{101}$ Diese Schutzgelder bildeten eine nicht unbedeutende landesherrliche Einnahmequelle.

Um die wachsenden Kosten für die Hussitenkreuzzüge bestreiten zu können, war Friedrich jedoch immer öfter gezwungen, Kredite bei den sächsischen Juden aufzunehmen, von denen ein gewisser Abraham in Leipzig in dieser Zeit eine besonders bedeutende Stellung beim Markgrafen und späteren Kurfürsten einnehmen sollte. Von diesem Juden Abraham lieh sich die Kurfürstin Katharina beispielsweise im Frühjahr 1426700 rheinische Gulden, die zur Ausrüstung des Entsatzheeres für die belagerte Stadt Aussig dienen sollten. ${ }^{102}$

In den 1430er-Jahren nahmen die Ausgaben der Kurfürsten und Herzöge jedoch immer mehr zu, sodass Friedrich II. schließlich versuchte, zusätzliche Einnahmen durch die Einführung allgemeiner Steuern zu regenerieren. Ganz neu war dieser Gedanke nicht. Auf Reichsebene hatte König Sigismund bereits 1427 versucht, die Kosten für die Aufstellung neuer Kreuzzugsheere durch den „Hussitenpfennig“ aufzubringen. ${ }^{103}$

Wollte der Kurfürst nun auch die Finanzmittel der Städte und des Adels mobilisieren, musste er sie an seiner Herrschaft beteiligen. Daher wurden 1438 erstmals die Landstände in Leipzig zusammenberufen. Diese umfassten die Prälaten, Grafen, Ritter und Städte des Kurfürstentums. Die Stände bewilligten Friedrich schließlich die von ihm geforderte Bede, aus der bald eine dauerhafte Steuer wurde, forderten im Gegenzug jedoch für sich das Recht ein, sich auch ohne Aufruf des Kurfürsten in steuerlichen Fragen zu gemeinsamen Beratungen zusammenfinden zu dürfen. ${ }^{104}$ „Steuern wurden bewilligt oder sogar erst geschaffen, um

100 Vgl. CDS I/B/1 (wie Anm. 55), Nr. 402, S. 299 f.

101 Vgl. ebd., Nr. 605, S. 459.

102 Vgl. CDS I/B/4 (wie Anm. 13), Nr. 487, S. 319 f.; LÄмmerhirt, Juden (wie Anm. 98), S. 53-55, 77.

103 Vgl. Moraw, Staat und Krieg (wie Anm. 4), S. 97; Maximilian Lanzinner, Der gemeine Pfennig eine richtungsweisende Steuerform? Zur Entwicklung des Reichssteuersystems 1422 bis 1608, in: Peter Rauscher/Andrea Serles/Thomas Winkelbauer (Hg.), Das „Blut des Staatskörpers“. Forschungen zur Finanzgeschichte der Frühen Neuzeit (Historische Zeitschrift, Beiheft 56), München 2012, S. 261-318, hier S. 269271.

104 Josef Matzerath, Der erste Landtag in Sachsen, in: Ders., Aspekte sächsischer Landtagsgeschichte, Dresden 1998, S. 8-10, hier S. 9; Karlheinz Blaschke, Geschichte Sachsens im Mittelalter, Berlin 1990, S. 301; Herbert Helbig, Der wettinische Ständestaat. Untersuchungen zur Geschichte des Ständewesens und der landständischen Verfassung in Mitteldeutschland bis 1485 (Mitteldeutsche Forschungen 4), Münster/ 
Kredite zu bedienen“, ${ }^{105}$ konstatierte Wolfgang Reinhard in Bezug auf den frühmodernen „Kriegs-, Macht- und Steuerstaat“. Diese Darstellung hilft durchaus zu erklären, warum die sächsischen Stände nicht schon während der Hussitenkriege, sondern erst nach deren Abflauen zusammengetreten sind. Die nun bewilligten Steuern dienten weniger zur Deckung der Kriegs- als der Kriegsfolgekosten, u. a. der Tilgung der von Juden bewilligten Kredite. ${ }^{106}$ Obwohl die sächsischen Stände keine permanente Einrichtung darstellten, markierte ihre erste Zusammenkunft 1438 doch den Übergang vom mittelalterlichen Domänen- zum frühneuzeitlichen Steuerstaat, obwohl beide Formen landesherrschaftlicher Einkünfte noch lange Zeit parallel zueinander existierten. Eine wichtige Grundlage für den "Steuerstaat“ war die seit dem 14. Jahrhundert zunehmende Geldwirtschaft, wodurch aus der nichtmonetären Sachabgabe des Lehnssystems die Geldsteuer des frühneuzeitlichen Staates werden konnte. ${ }^{107}$

Obwohl sich bereits hier die Ursprünge der politischen Bedeutung der sächsischen Stände ausmachen lassen, stellt dieser Vorgang im spätmittelalterlichen Europa kein Unikum dar, wie schon Otto Hintze herausarbeitete. ${ }^{108}$ In Frankreich fanden sich bereits Mitte des 14. Jahrhunderts infolge der Auftaktniederlagen des französischen Heeres im Hundertjährigen Krieg Adel, Klerus und Städte zu einem Parlament zusammen, um über eine allgemeine Besteuerung des Landes zu

Köln 1955, S. 418-425; Rogge, Die Wettiner (wie Anm. 7), S. 159. Rogge betont ausdrücklich: „Gefördert wurde diese Entwicklung jedoch nicht allein durch die Folgen der Hussitenkriege, sondern auch von den Familienkonflikten der Wettiner, die um die Jahrhundertmitte wieder heftig entflammten."

105 Wolfgang Reinhard, Geschichte des modernen Staates, München 2007, S. 74.

106 Diese Deutung klingt auch bei Herbert Helbig an: „Die zahlreichen Züge Friedrichs des Streitbaren gegen die Ketzer, die Unterhaltung verschiedener Grenzfestungen und die Auslösung der vielen Gefangenen verursachten hohe Ausgaben. Schlimmer noch war es, daß die ewigen Unruhen störende Stockungen in Handel und Gewerbe verursachten, als deren Folgen wiederum eine Verminderung der fürstlichen Einkünfte an Zöllen, Geleitsgeldern u. ä. eintrat“; Helbig, Der wettinische Ständestaat (wie Anm. 103), S. 416.

107 Vgl. Reinhard, Geschichte des modernen Staates (wie Anm. 104), S. 57 f., 70. Zur Entwicklung der spätmittelalterlichen Fürstenherrschaft und der Herausbildung der Stände allgemein: ERnST SCHUbERT, Fürstliche Herrschaft und Territorium im späten Mittelalter (Enzyklopädie deutscher Geschichte 35), München 1996, S. 38-49. Schubert bedient allerdings mehrheitlich Beispiele aus dem süddeutschen Raum.

108 „Damit wird die Kriegsrüstung zu einer Finanzfrage; und wir sehen die Herrscher bestrebt, seit dem 14.-15. Jahrhundert, von ihren Vasallen und sonstigen Untertanen Geldmittel anstatt des Naturalkriegsdienstes zu erhalten, um sich in kriegerische Rüstung zu setzen. Das ist ein Hauptanlaß zur Ausbildung oder wenigstens zur häufigen Berufung von Ständeversammlungen, Parlamenten, Etats généreaux und Landtagen geworden“; Отто Hintze, Staatsverfassung und Heeresverfassung. Vortrag gehalten in der Gehe-Stiftung zu Dresden am 17. Februar 1906, Dresden 1906, S. 19. Des Weiteren: KeRsten KrÜGER, Die landständische Verfassung (Enzyklopädie deutscher Geschichte 67), München 2003, S. 4-10. 
debattieren, welche der Versorgung des Heeres dienen sollte. ${ }^{109}$ Im Deutschordensstaat in Preußen sah sich Hochmeister Heinrich von Plauen 1411/12 gezwungen, die Ritterschaft und die Städte zu einem Landtag zusammenzurufen, um erstmals eine allgemeine Steuer zu erheben. Diese diente zum einen zur Tilgung der Kontributionen, die im Zuge des Ersten Thorner Friedens (1411) an Polen zu zahlen waren, zum anderen der Finanzierung von Söldnertruppen, auf denen die militärische Macht des Ordens beruhte, nachdem ein Großteil der Ritterbrüder in der Schlacht bei Tannenberg (1410) gefallen war. Zwar wurde der Hochmeister bald von den Großgebietigern des Ordens abgesetzt, aber die einmal einberufenen Stände verlangten weiterhin nach politischer Teilhabe. Diese wurde ihnen allerdings von den Nachfolgern von Plauens verweigert, was 1440 zunächst zur Gründung des Preußischen Bundes als Körperschaft zur Vertretung der Interessen von Städten und Ritterschaft führte. Als der Orden den Bund 1454 durch Kaiser Friedrich III. für illegal erklären ließ, sagten die preußischen Städte dem Hochmeister sogar die Huldigung auf und unterwarfen sich dem König von Polen, dem nach dem Dreizehnjährigen Krieg im Zweiten Thorner Frieden 1466 schließlich die westliche Hälfte des Ordensstaates zugesprochen wurde. ${ }^{110}$

Söldnerheere - Steuern - Ständevertretung, diese Ereigniskette lässt sich also in vielen spätmittelalterlichen Herrschaften beobachten. Sicherlich wurden die einmal aufgebrachten Steuern nicht nur zur Kriegsfinanzierung verbraucht - vom stehenden Heer ist Sachsen noch weit entfernt - aber in Zeiten fast permanenter militärischer Konflikte verschlangen sie weiterhin einen beträchtlichen Teil der herrschaftlichen Einnahmen. Daher kann bereits für das 15. Jahrhundert der von Otto Hintze geprägte Begriff vom Militär als „Schwungrad an der Staatsmaschine " 111 geltend gemacht werden.

Doch nicht nur die Etablierung der Landstände und die Erhebung von Steuern verweisen auf sich ausbildende frühneuzeitliche Herrschaftsmittel. Zur Erhebung

109 Vgl. Clifford J. Rogers, The Military Revolutions of the Hundred Years' War, in: The Journal of Military History 57 (1993), S. 241-278; Joachim Ehlers, Der Hundertjährige Krieg, München 2009, S. 48-56.

110 Hierzu allgemein: Marian Biskup, Der Deutsche Orden und die Freiheit der großen Städte in Preußen vom 13. bis zur Mitte des 15. Jahrhunderts, in: Udo Arnold (Hg.), Stadt und Orden. Das Verhältnis des Deutschen Ordens zu den Städten in Livland, Preußen und im Deutschen Reich (Quellen und Studien zur Geschichte des Deutschen Ordens 44), Marburg 1993, S. 112-128; Roman CzajA, Die Krise der Landesherrschaft. Der Deutsche Orden und die Gesellschaft seines Staates in Preußen in der ersten Hälfte des 15. Jahrhunderts, in: Ders./Jürgen Sarnowsky (Hg.), Die Ritterorden in Umbruchsund Krisenzeiten (Ordines Militares 16), Toruń 2011, S. 159-171; Johannes Voigt, Geschichte Preußens von den ältesten Zeiten bis zum Untergange der Herrschaft des Deutschen Ordens, Bd. 8: Die Zeit von Hochmeister Konrad von Erlichshausen 1441 bis zum Tode des Hochmeisters Ludwig von Erlichshausen 1467, Königsberg 1838.

111 Отто Hintze, Geist und System der preußischen Verwaltung um 1740, in: Ders. (Hg.), Die Behördenorganisation und die allgemeine Staatsverwaltung Preußens im 18. Jahrhundert (Acta Borussica. Denkmäler der Preußischen Staatsverwaltung im 18. Jahrhundert), Berlin 1901, S. 2-56, hier S. 23. 
der Steuern und zur Koordinierung von Söldnerheeren bedurfte es eines entsprechenden Beamtenapparats. ${ }^{112}$ Die an die Städte gerichtete Forderung von Ernst und Albrecht aus dem Jahr 1474, ihr militärisches Potenzial aufzulisten, diente zudem einer statistischen Erfassung des Wehrpotenzials des Landes. Den Ausgangspunkt hierfür bildete eine entsprechende kaiserliche Aufforderung auf dem Nürnberger Reichstag, um einen Anschlag für den nächsten Türkenfeldzug aufzustellen - erneut lieferte ein Krieg den Anlass, Wehr- und Steuerpotenzial eines Landes aufzuzeichnen. Laut Hubert Ermisch handelte es sich in Sachsen um den ersten Versuch einer statistischen Erfassung. ${ }^{113}$

Im ausgehenden 15. Jahrhundert profitierten die Wettiner von neuen Silberfunden im westlichen Erzgebirge nahe Schneeberg und später bei Annaberg, wodurch die Einnahmen aus dem Bergregal wieder stiegen. Von 1470 bis 1483 wurde im Schneeberger Raum Silber im Wert von 700000 Gulden zutage gefördert. ${ }^{114}$ Diese flossen seit 1470 in eine zentrale Kasse, die der Rentmeister Johann Mergenthal aus der Hof- und Zentralverwaltung hatte herauslösen lassen. Die zweite wichtige Einnahmequelle bestand in der Ende 1475 vom Landtag bewilligten Tranksteuer auf Bier und Wein, welche jährlich 20344 Gulden einbrachte. Hierzu kamen noch Zolleinnahmen, sodass die Einkünfte Ernsts und Albrechts zwischen 1482 und 1485 schätzungsweise 100000 Gulden betrugen. ${ }^{115}$

Damit gehörten die Wettiner zwar zu den reichsten Fürsten des Reiches, dennoch konnten diese Einnahmen bei weitem nicht die Kosten decken, die die Kriege des späten 15. Jahrhunderts verursachten. Allein die friesischen Feldzüge Herzog Albrechts kosteten Unsummen und rissen ein enormes Loch in den wettinischen Haushalt, da König Maximilian seine Schulden bei Albrecht nur zögerlich abbezahlte. Diese stiegen von 52265 Gulden im Sommer 1489 auf 301928 Gulden im Jahr 1494.116

\section{Fazit}

Der von Michael Roberts und seinen Nachfolgern beschriebene „revolutionäre“ Wandel im europäischen Heerwesen und der dadurch hervorgerufene Staatsbildungsprozess lässt sich bereits im Spätmittelalter nachweisen und zwar nicht nur in Meißen-Sachsen, sondern in fast ganz Europa. Daher erscheint es durchaus gerechtfertigt zu behaupten, eine eigentliche Militärische Revolution hat wenn

112 Vgl. Kroener, Kriegswesen (wie Anm. 5), S. 15; Schubert, Fürstliche Herrschaft (wie Anm. 106), S. 15-17.

113 Vgl. ERmisch, Zur Statistik der sächsischen Städte (wie Anm. 51), S. 145-147.

114 Hierzu: Albert Schröder, Beiträge zur Geschichte der Silbererzgewinnung in Schneeberg, in: NASG 52 (1931), S. 18-29; Uwe Schirmer, Kursächsische Staatsfinanzen (1456-1656). Strukturen - Verfassung - Funktionseliten (Quellen und Forschungen zur sächsischen Geschichte 28), Stuttgart 2006, S. 92-94, 112 f.

115 Vgl. Rogge, Die Wettiner (wie Anm. 7), S. 177 f.

116 Vgl. BaKs, Albrecht (wie Anm. 53), S. 114. 
überhaupt nur im Spätmittelalter stattgefunden. In dieser Zeit fand der Wandel vom Lehnwesen zum Berufskriegertum statt und zwang die Fürsten, zu deren Finanzierung neue Geldquellen zu erschließen. Hierfür wurden allgemeine Steuern erhoben, wofür die Landesherren jedoch die Einwilligung der Stände - in Form von Adel, Kirche und Städten - benötigten, die somit Gelegenheit zu politischer Partizipation erlangten. Alle folgenden Strukturwandel des Militärs und des Herrschaftssystems bis in die Napoleonische Zeit stellen dann nur einen nicht immer linearen und ebenso wenig als progressiv zu charakterisierenden evolutionären Wandel dar, bei dem auf vorhandenen Strukturen aufgebaut wurde. Unter diesem Blickwinkel ließe sich die spätmittelalterliche und frühneuzeitliche europäische Militärgeschichte durchaus neu als die Geschichte einer „Militärischen Evolution" schreiben, innerhalb welcher ein revolutionärer Wandlungsprozess lediglich den Beginn eines langen von unregelmäßigen Entwicklungsschüben begleiteten Transformationsprozesses bildete. 117

An der Geradlinigkeit der besonders von den Vertretern des Konzepts der Militärischen Revolution vertretenen Entwicklung „Militär - Steuern - Ständevertretung" wurde jedoch gerade innerhalb der deutschen Forschungsgemeinde Kritik geübt. „Eine Militärgeschichte, die militärische Innovationen, seien sie nun technischer, taktischer oder organisatorischer Art, als Motor soziopolitischer Veränderungen begreift, verwechselt jedoch Ursache und Wirkung. Es waren in erster Linie externe strukturelle Bedingungen, Welt- und Gesellschaftsbilder, die $\mathrm{zu}$ Veränderungen in der zeitgenössischen Kriegführung führten und deren Effizienz zu steigern vermochten “, 118 schreibt Bernhard R. Kroener. Dabei bezieht er sich auf die tiefschürfenden Änderungen des 14. Jahrhunderts, den durch den klimatischen Wandel hervorgerufenen und die Pestwellen verstärkten Bevölkerungsrückgang, den Rückgang landwirtschaftlicher Erträge, der dadurch hervorgerufenen Preissteigerung für landwirtschaftliche Produkte, der Landflucht und dem dadurch wiederum bewirkten Überangebot an Arbeitskräften in den Städten, das einen Preisverfall für gewerbliche Produkte hervorrief und gleichzeitig erst ein personelles Angebot für große Söldnerheere schuf. Damit einher ging auch die Krise des Adels, für den der Solddienst eine neue lukrative Erwerbsmöglichkeit darstellte, insbesondere weil sich sein Verhältnis zum Landesherrn gewandelt hatte. Doch diese Betrachtungen laufen zwangsläufig auf die berühmte Frage nach Huhn oder Ei hinaus, die sich nur dann auflösen lässt, wenn sich klären lässt, ob das durch die oben skizzierten Krisen geschaffene neue Wehrpotenzial auch aufgrund der im selben Zug entstehenden bewaffneten Konflikte abgerufen wurde oder ob der soziale Wandel des späten 14. Jahrhunderts in keinem Zusammenhang mit den großen militärischen Auseinandersetzungen des frühen 15. Jahrhunderts steht.

117 Diesen Ansatz formulierte ähnlich bereits Clifford J. Rogers, vgl.: Rogers, The Military Revolution Debate (wie Anm. 6), S. 227.

118 Kroener, Kriegswesen (wie Anm. 5), S. 57. 